\title{
Identifying Droughts Affecting Agriculture in Africa Based on Remote Sensing Time Series between 2000-2016: Rainfall Anomalies and Vegetation Condition in the Context of ENSO
}

\author{
Karina Winkler 1,2,3,*, Ursula Gessner ${ }^{2}$ and Volker Hochschild ${ }^{3}$ \\ 1 Company of Remote Sensing and Environmental Research (SLU), Kohlsteiner Str. 5, 81243 Munich, Germany \\ 2 German Remote Sensing Data Center (DFD), German Aerospace Center (DLR), 82234 Wessling, Germany; \\ ursula.gessner@dlr.de \\ 3 Institute of Geography, University of Tuebingen, Ruemelinstr. 19-23, 72070 Tuebingen, Germany; \\ volker.hochschild@uni-tuebingen.de \\ * Correspondence: karina.winkler@posteo.net
}

Received: 13 July 2017; Accepted: 29 July 2017; Published: 11 August 2017

\begin{abstract}
Droughts are amongst the most destructive natural disasters in the world. In large regions of Africa, where water is a limiting factor and people strongly rely on rain-fed agriculture, droughts have frequently led to crop failure, food shortages and even humanitarian crises. In eastern and southern Africa, major drought episodes have been linked to El Niño-Southern Oscillation (ENSO) events. In this context and with limited in-situ data available, remote sensing provides valuable opportunities for continent-wide assessment of droughts with high spatial and temporal resolutions. This study aimed to monitor agriculturally relevant droughts over Africa between 2000-2016 with a specific focus on growing seasons using remote sensing-based drought indices. Special attention was paid to the observation of drought dynamics during major ENSO episodes to illuminate the connection between ENSO and droughts in eastern and southern Africa. We utilized Tropical Rainfall Measuring Mission (TRMM)-based Standardized Precipitation Index (SPI) with $0.25^{\circ}$ resolution and Moderate-resolution Imaging Spectroradiometer (MODIS)-derived Vegetation Condition Index (VCI) with $500 \mathrm{~m}$ resolution as indices for analysing the spatio-temporal patterns of droughts. We combined the drought indices with information on the timing of site-specific growing seasons derived from MODIS-based multi-annual average of Normalized Difference Vegetation Index (NDVI). We proved the applicability of SPI-3 and VCI as indices for a comprehensive continental-scale monitoring of agriculturally relevant droughts. The years 2009 and 2011 could be revealed as major drought years in eastern Africa, whereas southern Africa was affected by severe droughts in 2003 and 2015/2016. Drought episodes occurred over large parts of southern Africa during strong El Niño events. We observed a mixed drought pattern in eastern Africa, where areas with two growing seasons were frequently affected by droughts during La Niña and zones of unimodal rainfall regimes showed droughts during the onset of El Niño. During La Niña 2010/2011, large parts of cropland areas in Somalia $(88 \%)$, Sudan $(64 \%)$ and South Sudan $(51 \%)$ were affected by severe to extreme droughts during the growing seasons. However, no universal El Niño- or La Niña-related response pattern of droughts could be deduced for the observation period of 16 years. In this regard, we discussed multi-year atmospheric fluctuations and characteristics of ENSO variants as further influences on the interconnection between ENSO and droughts. By utilizing remote sensing-based drought indices focussed on agricultural zones and periods, this study attempts to contribute to a better understanding of spatio-temporal patterns of droughts affecting agriculture in Africa, which can be essential for implementing strategies of drought hazard mitigation.
\end{abstract}

Keywords: Africa; drought; agriculture; MODIS; TRMM; drought indices; SPI; VCI; ENSO 


\section{Introduction}

Droughts are amongst the most destructive natural hazards and can arise virtually everywhere on the globe [1]. Generally, three stages of drought can be distinguished according to its duration and affected component of the hydrological cycle: meteorological, agricultural and hydrological drought. Triggered by a rainfall deficit, agricultural droughts are characterized by reduced soil moisture and, hence, a lacking water supply to vegetation [2,3]. Droughts can affect both ecosystems and society in multiple ways by, on the one hand, being main drivers for land degradation and desertification and, on the other hand, involving socio-economic impacts such as crop failure, food shortages, famine, malnutrition, deaths and mass migration [4]. However, agricultural activity itself, including flow regulation and irrigation practices, may also lead to reduced water availability and, thus, conditions of agricultural drought [5]. In regard to a growing population and the ongoing climate change, water and food security are major challenges facing humanity [6]. The assessment of droughts affecting agricultural areas in Africa is highly relevant. With rainfall as the limiting factor for farming and many African countries strongly relying on rain-fed agriculture, droughts can lead to severe socio-economic consequences [7]. In total, drought events have caused more than 800,000 deaths and affected about 262 million people in Africa during 1900-2013 [8]. What is more, severe dry episodes in southern and eastern Africa have often been linked with the effects of El Niño-Southern Oscillation (ENSO), leading to regional precipitation and temperature anomalies around the globe [9]. Considering the recent drought during El Niño 2015/2016, one of the strongest events of recorded history, and its devastating effects on agriculture and food security over large parts of Africa [10], understanding and monitoring ENSO-related droughts are of major concern for implementing measures of adaption to drought hazards.

In this context, remote sensing data and methods are critical tools for studying the spatio-temporal evolution and the underlying drivers of droughts due to limited availability and inconsistency of drought-related in-situ data [11,12]. Earth observation can bridge this gap by providing the opportunity to obtain continuous, consistent and timely information on meterological, hydrological and biophysical parameters over large areas and long time periods. Thus, with recent advances in techniques and an increased data availability, remote sensing-based time series analysis has become highly relevant for environmental monitoring [13,14]. In the last decades, remote sensing-based drought indices have been established in order to quantify the strength, duration and spatial extent of droughts. These indicators rely on meteorological, soil, hydrological or vegetation-related parameters $[15,16]$. Numerous studies and approaches dealing with remote sensing-based drought monitoring and with a focus on the African continent have been published. In this connection, operational approaches on global- and continental-scale drought monitoring [6,17-20] as well as remote sensing-based studies on droughts in Africa focussing on selected regions and/or periods are to be mentioned. Here, topics of current interest are the ongoing debate on the Sahelian "greening" [21-23], drought during 2010/2011 in the Horn of Africa [13,24-26], rainfall and vegetation-related drought dynamics in southern Africa [27-30], continental-scale drought assessment $[12,31,32]$ as well as the relation between droughts in Africa and ENSO [9,33-36]. However, either studies accounted for drought assessment on rather small regional scales and did not assess the continental level or little attention was paid to drought affecting agriculturally relevant areas and time periods.

The study aims to give a retrospective insight into the spatio-temporal evolution of agriculturally relevant droughts over Africa during 2000-2016 in consideration of growing seasons and agricultural areas. This has not yet been carried out on a continental scale. By further illuminating the occurrence of droughts in eastern and southern Africa during major ENSO phases, the connection between ENSO and drought indices is examined. The main objective of the study is to contribute to a better understanding of regional patterns of agriculturally relevant droughts and its dependencies. The methodology is based on classical drought indices derived from remotely sensed data. Here, agricultural drought is not assessed in a direct way, quantifying soil moisture. We rather take rainfall deficit and vegetation condition as proxies indicating agriculturally relevant droughts. In particular, we utilize Tropical 
Rainfall Measuring Mission (TRMM) precipitation estimates ( $0.25^{\circ}$ resolution) for calculating the Standardized Precipitation Index (SPI) as a first drought index. Secondly, we use Moderate-resolution Imaging Spectroradiometer (MODIS) surface reflectance (500 m resolution) to derive the Normalized Difference Vegetation index (NDVI) for determining the timing of growing seasons as well as the Vegetation Condition Index (VCI) as a second drought index. Different to existing studies, this analysis exclusively focuses on agricultural areas and agriculturally relevant seasons.

\section{Study Area}

The study area covers the African continent. Being the second largest continent on earth, Africa covers about 30 million $\mathrm{km}^{2}$ and borders the Mediterranean Sea in the North, the Atlantic Ocean in the West, the Indian Ocean in the East and the Red Sea in the Northeast [37].

As a consequence of convective rainfalls and air transportation between the Inner Tropical Convergence Zone (ITCZ) and subtropical high pressure cells on each of the northern and southern sides, precipitation can be considered as a key factor of the African climate. In total, Africa consists of areas under arid (57.2\% of surface area), tropical $(31.0 \%)$ and temperate $(11.8 \%)$ climate. The arid climate zone comprises an extensive area under warm desert climate, regions under cold desert as well as semi-arid steppe climate [37,38]. The distribution of soil types across the African continent is directly linked to its climate zones. Among the most productive soils for agriculture in Africa are Luvisols, Vertisols, Chernozems, Kastanozems and Fluvisols, which are ideally suited for agriculture and represent about $10 \%$ of the African farmland, mainly situated south of the Sahel (Senegal, Mali, Burkina Faso, Ghana, Togo, Benin, Nigeria, Chad) and in southern Africa, e.g., Mozambique, Zambia, Zimbabwe and South Africa [37,39]. Figure 1 displays the spatial distribution of European Space Agency (ESA ) Climate Change Initiative (CCI ) land cover classes [40] in Africa, including the location of major agricultural zones. In general, forests, savannah, grassland and deserts are the major vegetation zones of Africa. The highest primary productivity and biodiversity is generally found in the tropical climate zone [37,39]. Seasonal precipitation is the dominant climatic force of savannah biomes. Within the semi-desert biome, which is regarded as a transition zone between savannah and desert areas, short grasses and typical iconic acacias are predominant. With a generally very low biomass, the desert biome consists of vegetation highly adapted to precipitation deficits and extreme temperatures. What is more, a zone of temperate grassland is located in southern Africa [39].

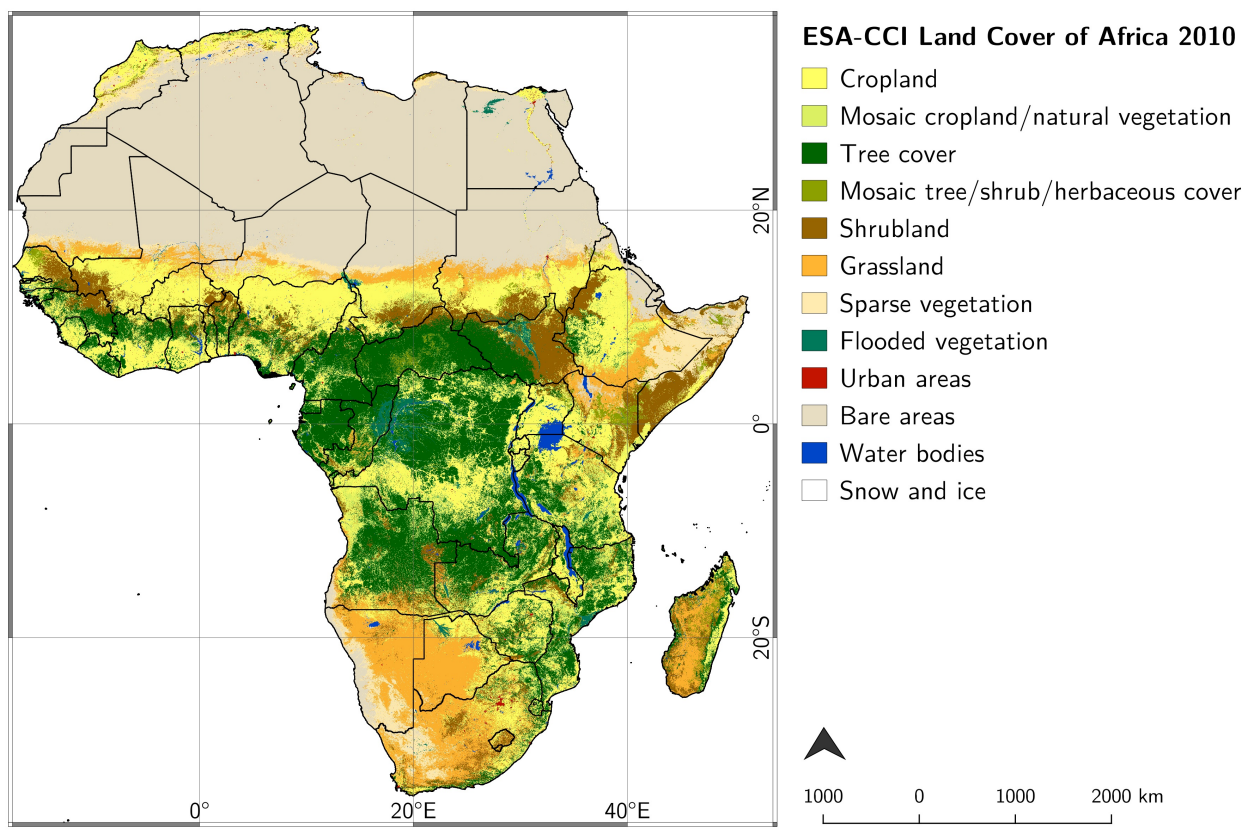

Figure 1. Land cover of Africa for 2008-2012, data source: [40]. 


\section{Materials and Methods}

Figure 2 gives an overview of the major methodological steps applied in this work. Firstly, we used remote sensing-based data sets (see Table 1) to derive meteorological and vegetation-based indices for agriculturally relevant droughts and to identify cropland areas. Secondly, phenological information was extracted from the temporal vegetation profiles based on the NDVI in order to characterize the average timing and duration of the growing season. On that basis, spatio-temporal patterns of agriculturally relevant droughts were detected and analysed for the period of 2000-2016.

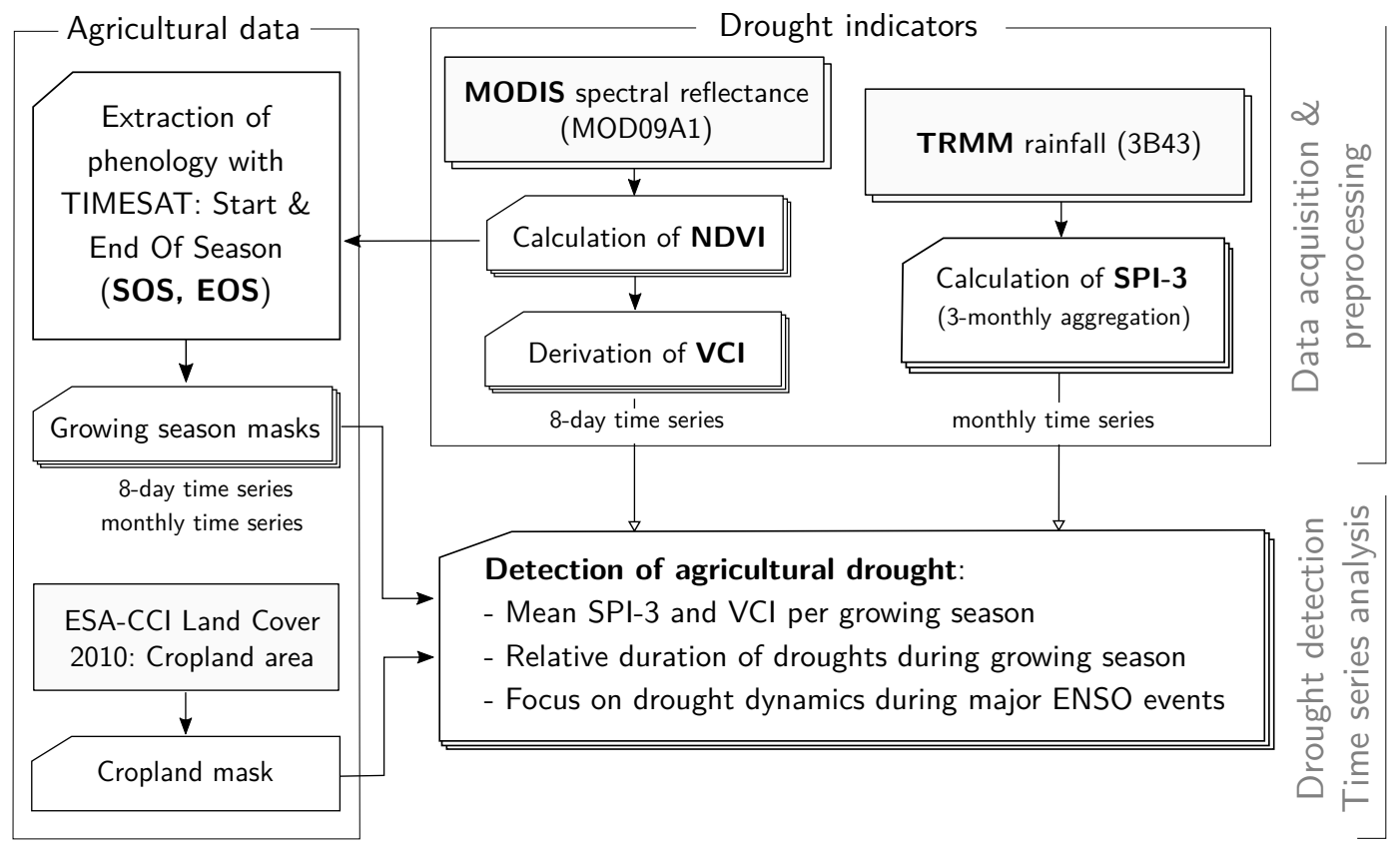

Figure 2. Schematic overview of the methodological approach.

Table 1. Remote sensing-based data sets and their specifications utilized in this study.

\begin{tabular}{llll}
\hline Dataset & TRMM 3B43 (V7) & MODIS MOD09A1 (V6) & ESA CCI-LC 2010 \\
\hline $\begin{array}{l}\text { Variable } \\
\text { Source }\end{array}$ & $\begin{array}{l}\text { Precipitation rate }(\mathrm{mm} / \mathrm{h}) \\
\text { TRMM, gauge analysis }\end{array}$ & $\begin{array}{l}\text { Surface reflectance } \\
\text { MODIS }\end{array}$ & Land Cover classification \\
& $\begin{array}{l}\text { TEl coverage } \\
\text { 1 January 1998 to present }\end{array}$ & $\begin{array}{l}\text { 26 February 2000 to } \\
\text { present }\end{array}$ & MERIS and SPOT-Vegetation \\
Spatial coverage & $50^{\circ} \mathrm{S}$ to $50^{\circ} \mathrm{N}$ & Global & \\
Temporal resolution & 1 month & 8 days (composite) & Global \\
Spatial resolution & $0.25^{\circ} \times 0.25^{\circ}$ & $500 \mathrm{~m}$ & no time series \\
Data format & netCDF & HDF & GeoTIFF \\
\hline
\end{tabular}

\subsection{MODIS Data and Calculation of NDVI and VCI}

We derived a vegetation-based drought index based on 8-day composites of MODIS MOD09A1 Surface Reflectances with $500 \mathrm{~m}$ spatial resolution. These were retrieved for 41 granules covering the African continent for the study period of 26 February 2000 to 30 April 2016, which provided a data base totalling 30,668 images. The MOD09A1 product from MODIS-Terra, a near-polar orbiting satellite operated by the NASA, provides reflectance information of seven spectral bands in the form of 8-day composites [41].

We derived NDVI [42] and VCI [43] based on MOD09A1 spectral reflectance values of the RED (red) and NIR (near infrared) spectral domain, respectively. Here, VCI was retrieved from the generated 
time series of 8-daily NDVI images. The methodology relies on the computed minimum and maximum NDVI for each of the 46 composites representing days of year (DOY) 1-361:

$$
V C I=\frac{\left(N D V I_{j}-N D V I_{\min }\right) \times 100}{N D V I_{\max }-N D V I_{\min }},
$$

where $N D V I_{j}$ is the average NDVI over a composite period of 8 days, $N D V I_{\min }$ and $N D V I_{\text {max }}$ are the corresponding multi-year minimum and maximum NDVI for the specific analysed period of a year $[16,43,44]$. The VCI represents the health of the ground vegetation with values below $50 \%$ indicating below-normal conditions. It shows the potential of measuring drought intensity, duration and dynamics based on its large-scale impact on vegetation and has proven suitable for monitoring agricultural drought [44-46].

\subsection{TRMM Data and Derivation of SPI}

We used Tropical Rainfall Measuring Mission (TRMM), a joint mission of the U.S. National Aeronautics and Space Administration (NASA) and the Japanese National Space Development Agency (NASDA), as a data source for calculating the meteorological drought index SPI [47]. The product combines remotely sensed precipitation estimates with land surface gauge analyses [48]. Based on gridded monthly TRMM 3B43 (Version 7) rainfall data from March 2000 to April 2016 [49], we summed up the precipitation rates over the accumulation period of 3 months for each pixel. The 3-monthly aggregated SPI (SPI-3) is regarded as a suitable index for agricultural drought by the World Meteorological Organization (WMO) [50].

To derive SPI-3, rainfall data for each month of a year was analysed per pixel so as to estimate the key coefficients for a transformation of the observed frequency distribution to a gamma distribution

$$
g\left(x_{k}\right)=\frac{1}{\beta^{\alpha} \Gamma(\alpha)} x_{k}^{\alpha-1} e^{-x_{k} / \beta} \text { for } x_{k}>0
$$

with $\alpha>0$ as shape and $\beta$ as scale factor, $x_{k}>0$ as the amount of precipitation over $k$ consecutive months (here $k=3$ ) and $\Gamma(\alpha)$ as the gamma function

$$
\Gamma(\alpha)=\int_{0}^{\infty} y^{\alpha-1} e^{-y} d y
$$

via maximum likelihood estimation [51,52]. Afterwards, rainfall values were transformed to normally distributed SPI based on its respective cumulative probability value. Finally, the SPI is generally described as

$$
S P I=\frac{P-P^{*}}{\sigma_{P}}
$$

with $P$ as the aggregated precipitation for a certain time interval (here: 3 consecutive months), $P^{*}$ as the respective mean and $\sigma_{P}$ representing the standard deviation over the available data record for the studied interval [51]. We applied this calculation procedure using the language and software environment $R$ [53].

\subsection{Ancillary Data}

The European Space Agency (ESA) Climate Change Initiative (CCI) global land cover map representative for the epoch of 2008-2012 was used for differentiating agricultural from non-agricultural areas. The ESA CCI land cover product comes with $300 \mathrm{~m}$ spatial resolution and was generated implementing a multi-year and multi-sensor strategy [40]. To address agriculturally relevant drought, we extracted cropland-related land cover classes (Cropland, rainfed; Cropland, irrigated or post-flooded; Mosaic cropland/natural vegetation) and masked all non-cropland areas. 
To examine the effect of detected droughts on national agricultural production within the focal regions, we used yearly crop statistics from the FAOSTAT database [54]. Here, focus is on primary crops including vegetables, fruits, treenuts, cereals, pulses, roots and tubers, fibre crops and oil crops. We retrieved respective production quantity data for the period of 2000-2013.

\subsection{Extraction of Average Growing Season with TIMESAT}

A specific aim of this study is to assess droughts that affect agricultural production. In order to identify the timing and duration of major growing seasons, i.e., the periods that are relevant for agricultural production, we retrieved phenological information from previously generated NDVI time series using the software package TIMESAT 3.2 [55]. For each pixel, the average timing of the growing season was determined based on the multi-annual median NDVI time series as an indicator of the average change of vegetation throughout the year. After deriving the median for each 8-day composite of the NDVI data sets from 2000 to 2016, smoothing was carried out with the Savitzky-Golay filter using a window size of 4 [56]. We set the seasonal parameter of TIMESAT to 0 in order to consider areas of bimodal rainy seasons. To account for growing seasons spanning from one calendar year to another, the considered annual time span for extracting the timing of the growing season was set from DOY 241 of the first year (28/29 August) to DOY 361 of the second year (26/27 December). We used the $20 \%$ fraction of the amplitude for determining the Start (SOS) and End Of Season (EOS).

\subsection{Detection of Agriculturally Relevant Droughts}

To quantify the strength and duration of agriculturally relevant droughts over Africa for each seasonal year, we derived statistical and threshold-based parameters from time series of SPI- 3 and VCI. Note that a seasonal year starts at DOY 241 of the corresponding previous year (see Section 3.4). Based on the timing and duration of the growing season, the number of observations under drought conditions was extracted by using defined thresholds for both drought indices.

We categorized SPI-3 based on the classification of the WMO [50], which is outlined in Table 2. Accordingly, a threshold of -1 was used for SPI-3, with values below the threshold representing moderate to extreme drought conditions. With respect to VCI, Kogan [57] proposed a threshold of $35 \%$ for identifying drought conditions, which has widely been adopted by the drought monitoring community $[18,58]$. Related to this, we applied the drought classification stated by Klisch and Atzberger [59] for VCI (see Table 2), in which the 35\% threshold indicates moderate to extreme drought conditions. Consequently, all observations below the mentioned thresholds were counted for each pixel and related to the duration of the growing season. A parameter of relative duration of drought was produced for each seasonal year, representing the percentage duration of the growing season affected by drought. Since agricultural areas of eastern and southern Africa have been particularly affected by droughts during the study period, we chose these regions as focal areas.

Table 2. Drought categories based on SPI [50] and VCI [59].

\begin{tabular}{lll}
\hline Drought Category & SPI Range & VCI Range (\%) \\
\hline Extreme drought & $\mathrm{SPI} \leq-2$ & $\mathrm{VCI}<10$ \\
Severe drought & $-2<\mathrm{SPI} \leq-1.5$ & $10 \leq \mathrm{VCI} \leq 20$ \\
Moderate drought & $-1.5<\mathrm{SPI} \leq-1$ & $20<\mathrm{VCI}<35$ \\
No drought & $\mathrm{SPI}>-1$ & $\mathrm{VCI} \geq 35$ \\
\hline
\end{tabular}




\section{Results}

\subsection{Timing of Average Growing Season}

We derived the average start (SOS) and end (EOS) of one or-if applicable-two predominant growing seasons from multi-annual (2000-2016) MODIS-based median NDVI time series. The months of SOS and EOS are displayed in Figure 3. Due to the zonally graduated distribution of precipitation and climate zones across the African continent, growing seasons show spatially varying lengths and differing timing within the average seasonal year. Whereas the Sahel region exhibits a rather short growing season of about 3-5 months (see frame A in Figure 3), regions under tropical climatic conditions show growing seasons spanning more than 10 months, e.g., parts of Zambia, Zimbabwe and Mozambique (see frame B in Figure 3). Further, a bimodal distribution, where two growing seasons occur within one seasonal year, could be identified in the Nile delta, along the West African coast and in eastern Africa, especially in southwestern Ethiopia, Kenya, Somalia, Uganda, Rwanda and Burundi (see maps of SOS-2/EOS-2 in Figure 3, bottom).
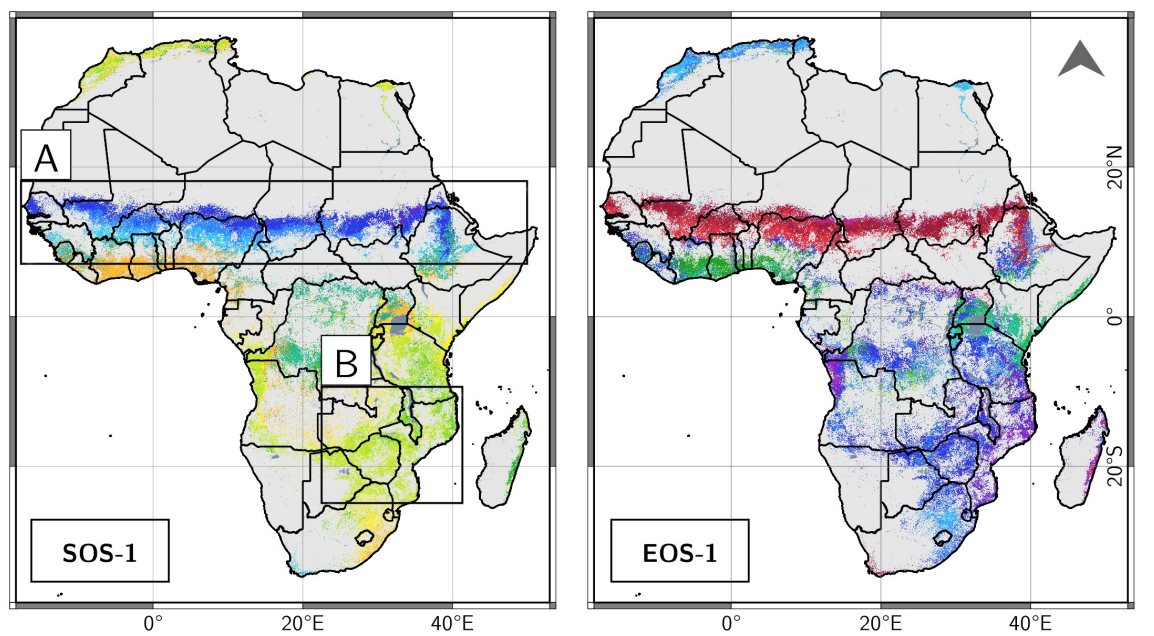

Month
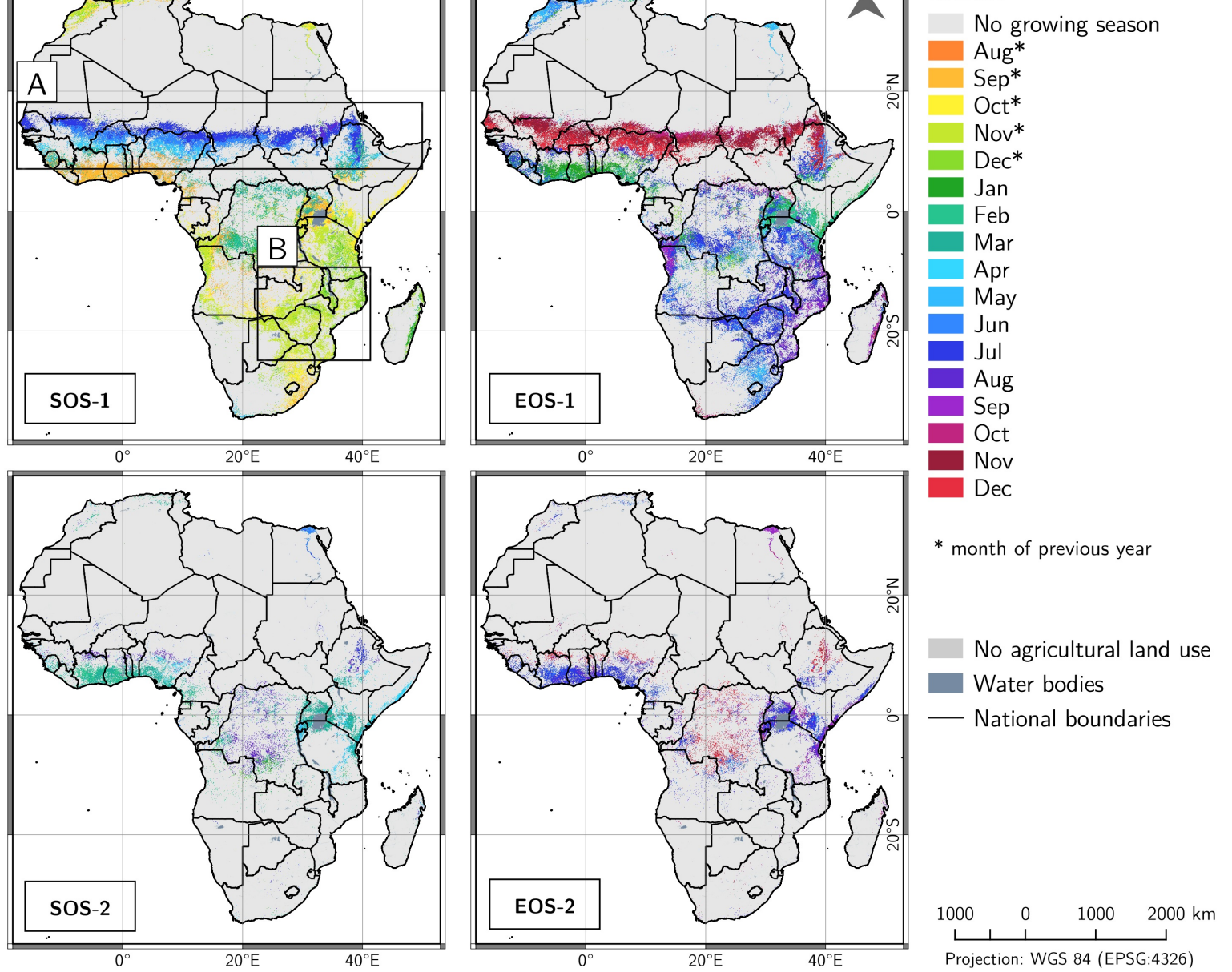

Figure 3. Start and end of detected growing seasons within average seasonal year (SOS-1/SOS-2: start of first/second growing season; EOS-1/EOS-2: end of first/second growing season) for agricultural areas in Africa. 


\subsection{Spatio-Temporal Patterns of Agriculturally Relevant Droughts over Africa}

Droughts occurring at agriculturally relevant growing seasons were analysed with respect to their intensity and duration. The spatio-temporal pattern of agriculturally relevant drought events over Africa in 2001-2016 is displayed as mean drought indices SPI-3 and VCI averaged per pixel over the growing season period (Figures 4 and 5). Figures 6 and 7 show the relative duration of drought conditions per growing season defined by the percentage of time that SPI-3- and VCI fall below a certain threshold (see Section 3.5). All in all, a temporally and spatially dynamic drought pattern could be revealed for the examined time period. Hereby, seasonal years of regionally widespread drought conditions, mostly located over core areas with particularly strong drought signals, were exhibited. For many areas in Africa, a larger part of the growing season was affected by droughts indicated by VCI, compared to the SPI-3-based signal (compare Figures 6 and 7). For the focal regions of eastern and southern Africa, Table 3 lists countries that were affected by severe agricultural droughts in a corresponding seasonal year of the study period. This information is based on visual examination of the retrieved SPI-3- and VCI-based images of drought durations during the agricultural growing season (Figures 6 and 7). Particularly drought-affected years, in which long-lasting droughts occurred across a major part of the focal region, are highlighted with a frame.

With focus on eastern Africa, 2009 and 2011 stand out as years of extensive agricultural droughts based on intensity and relative duration (see Table 3 and Figures 4-7). Additionally, VCI-based parameters reveal 2001, 2005 and 2006 as drought-affected seasonal years for Kenya and Somalia. Further, droughts were also detected for 2002/2003, 2008/2009 and 2015/2016 over central Ethiopia. In 2009, regions of major precipitation deficits were concentrated in northern Ethiopia and Eritrea as well as in southern Kenya and north-eastern Tanzania, consisting of large areas with mean SPI-3 ranging between -1 and -1.5 (Figures 4 and 6). The vegetation-related drought index basically retraces this pattern. However, VCI-based indicators reveal strikingly stronger drought conditions over northern Ethiopia, in the Rift Valley, and across Kenya, where agricultural droughts affected a large part of the growing season (Figures 5 and 7). According to mean SPI-3, the seasonal year 2011 was influenced by increased drought conditions in south-eastern Sudan and west Eritrea. Severe drought (mean SPI-3 between -1.5 and -2) could locally be found over southern Ethiopia, as well as moderate drought signals (mean SPI-3 between -0.5 and -1 , Figure 4) spanning across Kenya and southern Somalia. Here, the mean VCI drought signal is similar to SPI-3 and especially striking for Kenya and Somalia (VCI between $20 \%$ and 30\%, Figure 5). However, no significant drought indication is present over western Ethiopia and Uganda, where a precipitation deficit persisted during the growing season. The relative VCI-based drought duration pattern retraces the SPI-related signal and particularly highlights northern Kenya and Somalia, where over $50 \%$ of the growing season was influenced by drought (Figure 7).

Southern Africa was extensively affected by severe agricultural droughts during the seasonal years 2003 and 2015/2016 according to both drought severity and indicators of relative duration (see Table 3 and Figures 4-7). Further drought-affected years were 2005, 2007 and 2013. For 2003, both precipitation-based drought indicators expose drought conditions centred over north-eastern South Africa, Lesotho, eastern Botswana and west Zimbabwe (Figures 4 and 6). The vegetative drought pattern mostly agrees with these findings, but reveals a larger extent of drought-affected area. Accordingly, nearly the complete agricultural area of Botswana and Namibia was influenced by drought, showing a mean VCI of below 20\% (Figure 5) and relative drought durations of over $70 \%$ of the growing season (Figure 7). For 2016, which was analysed only until April, SPI-3-based drought signals are centred over South Africa/Lesotho and Namibia with mean SPI-3 as far as -1.5 and a relative drought duration of up to $100 \%$. Drought indications are also given in eastern South Africa and southernmost Mozambique, showing a large area of severe drought conditions according to both indicators. Strikingly, a core area with high drought signals situated over Mozambique, Malawi, eastern Zimbabwe and Zambia can be revealed from SPI-3. Values are below - 1 with a circular pattern of SPI-3 between -1.5 and -2 and drought durations of $80-100 \%$ of the growing season 
(Figures 4 and 6). However, no major vegetation-related drought signal is present for the mentioned region (Figures 5 and 7), which marks the area of strongest deviations between SPI-3- and VCI-based drought patterns.

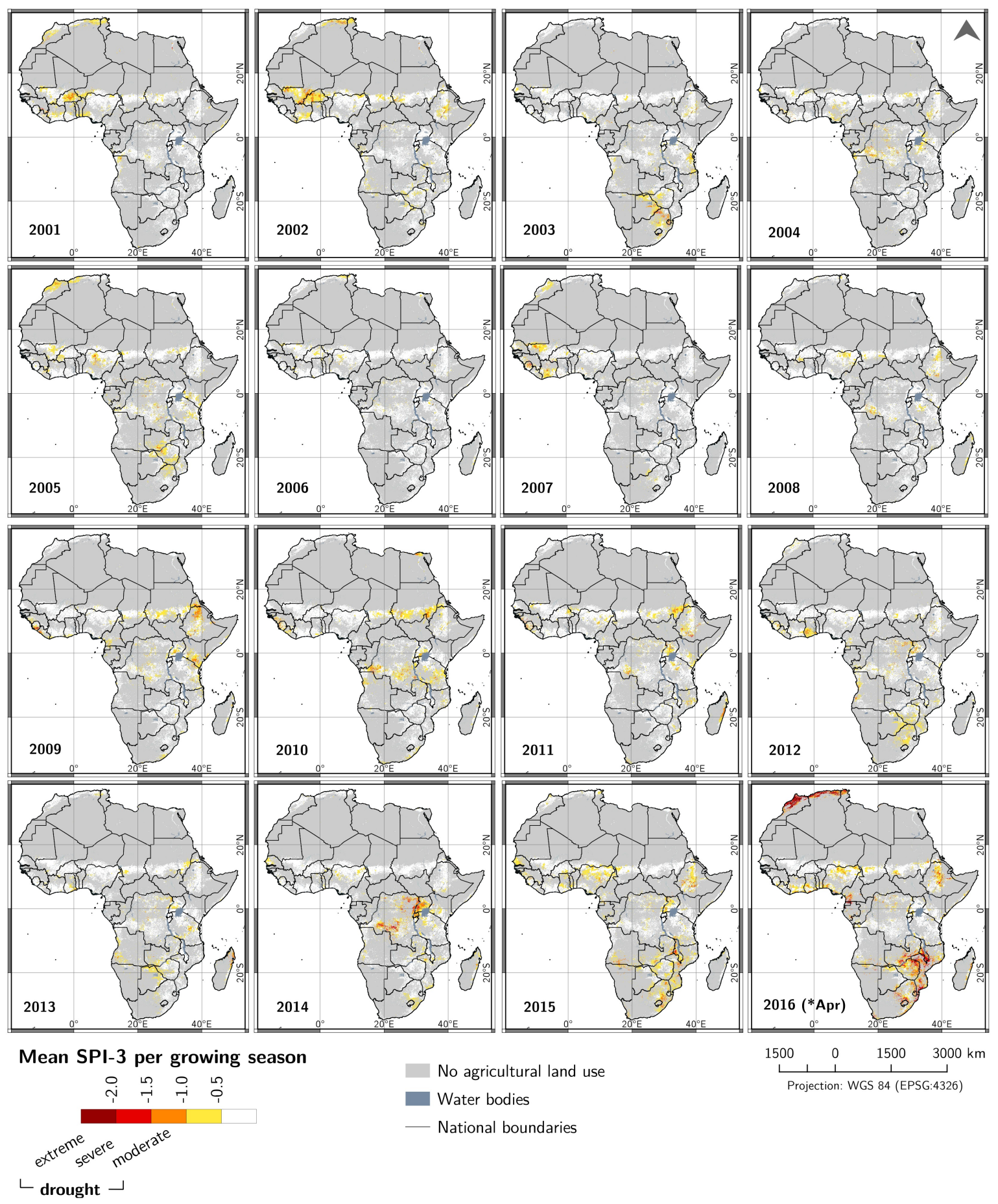

Figure 4. Intensity of drought: Mean SPI-3 per growing season from 2001 to 2016 (seasonal years). The lower the SPI-3, the more intense is the drought. 


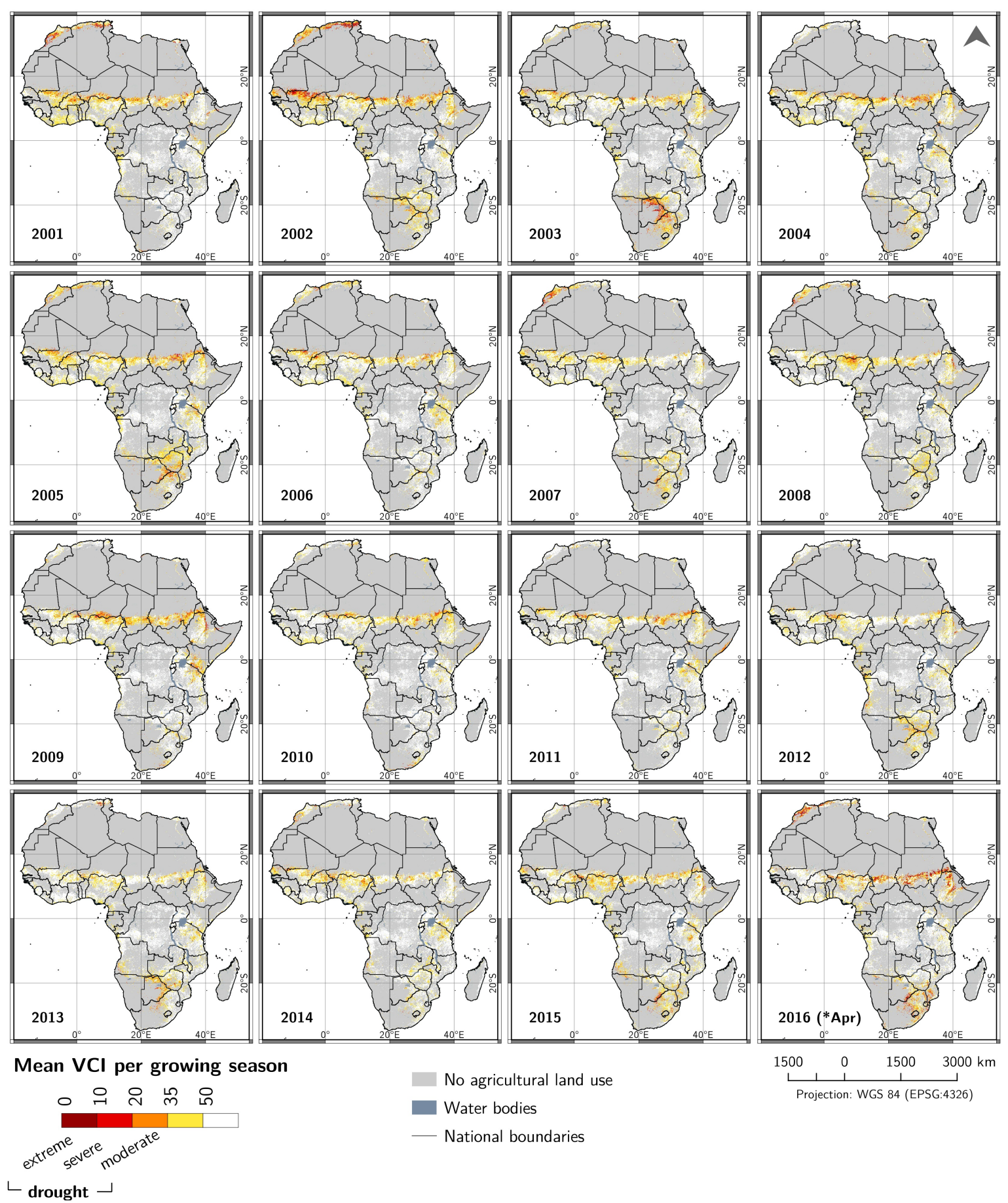

Figure 5. Intensity of drought: Mean VCI per growing season from 2001 to 2016 (seasonal years). The lower the VCI, the more intense is the drought. 


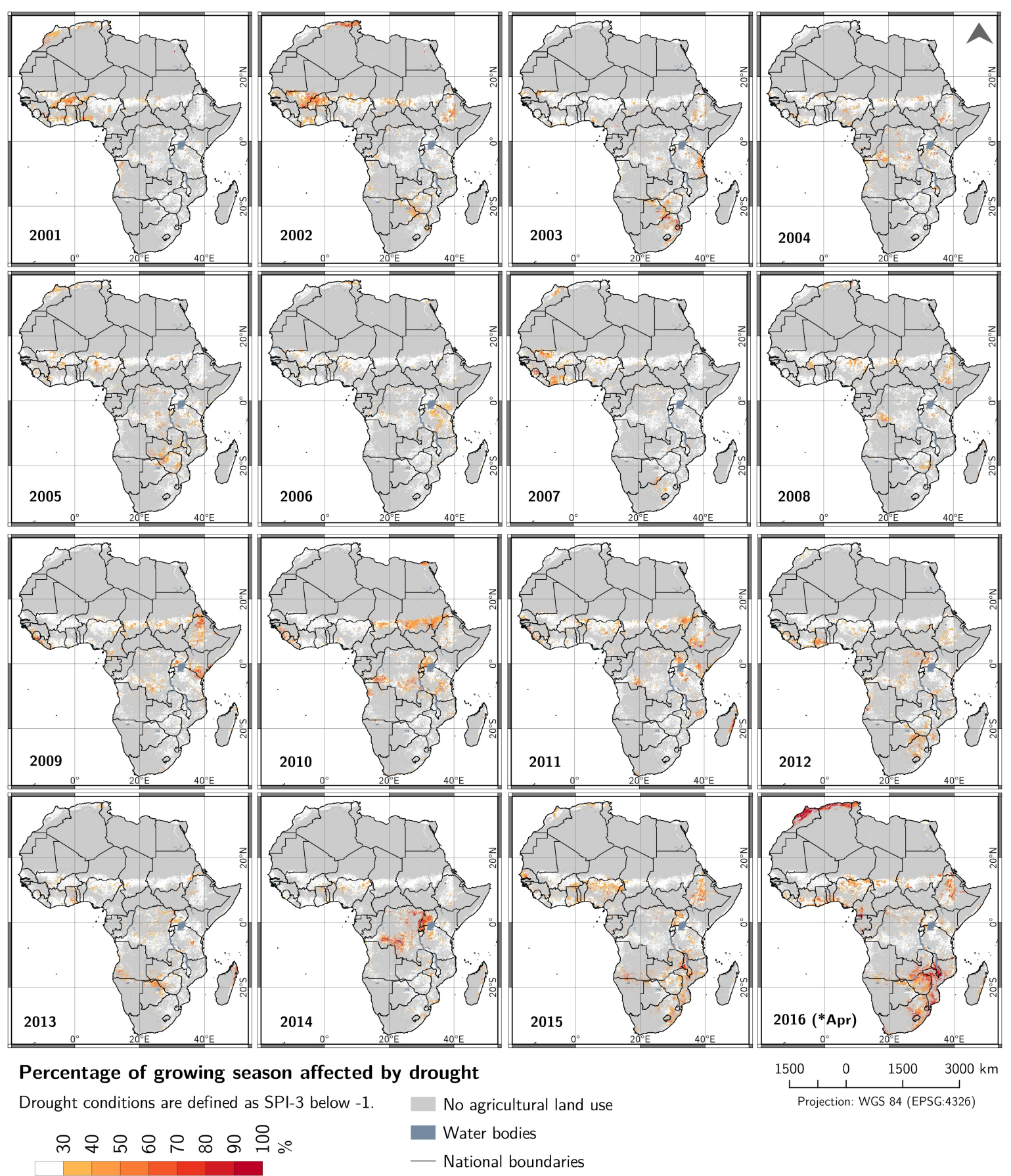

Figure 6. Relative duration of drought: Percentage of growing season affected by drought events (SPI-3 below -1) from 2001 to 2016 (seasonal years). 


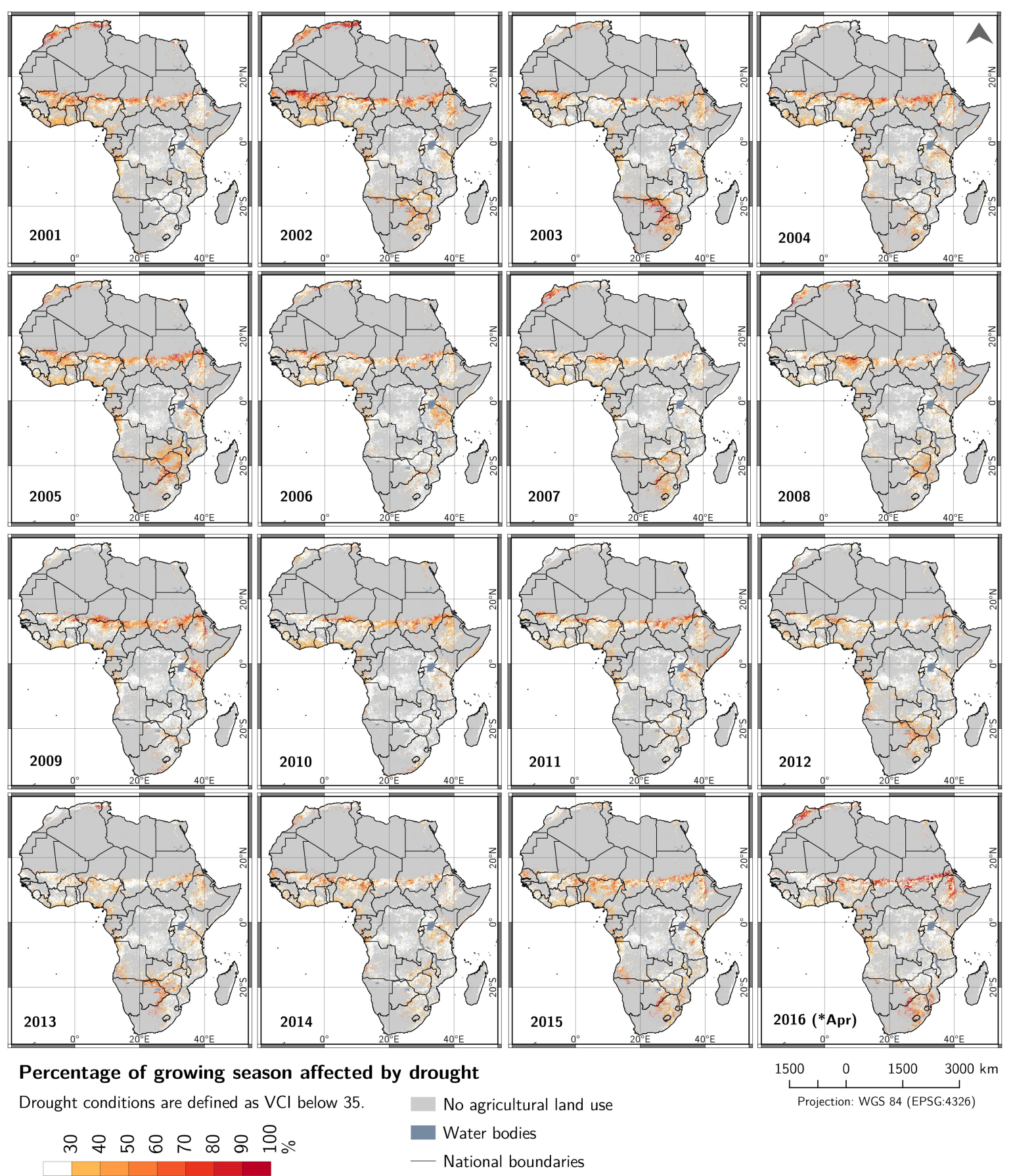

Figure 7. Relative duration of drought: Percentage of growing season affected by drought events (VCI below 35) from 2001 to 2016 (seasonal years). 
Table 3. Seasonal years and countries of focal regions affected by agriculturally relevant droughts based on drought indices SPI-3 (Figure 6) and VCI (Figure 7). Matches of both indices are displayed in bold.

\begin{tabular}{|c|c|c|c|}
\hline \multirow{3}{*}{ Region } & \multirow{3}{*}{ Years } & \multicolumn{2}{|l|}{ Countries * Affected by Drought Based on } \\
\hline & & Rainfall Anomalies & Vegetation Condition \\
\hline & & (Relative Duration of SPI-3 $<-1$ ) & (Relative Duration of $\mathrm{VCI}<35$ ) \\
\hline \multirow{16}{*}{$\begin{array}{l}\text { Eastern } \\
\text { Africa }\end{array}$} & $2000 / 2001$ & & ER ET KE SD SO SS \\
\hline & $2001 / 2002$ & ER ET SD & ER ET KE SD SS TA \\
\hline & $2002 / 2003$ & ER ET KE TA & ER ET SD SS KE TA \\
\hline & $2003 / 2004$ & BI ET SD TA & ER ET KE SD SO SS TA \\
\hline & $2004 / 2005$ & BI KE SD SO TA & ER ET KE SD SS TA \\
\hline & $2005 / 2006$ & KE TA & ER ET KE SD SO TA UG \\
\hline & $2006 / 2007$ & $\mathrm{SO}$ & ET SD \\
\hline & $2007 / 2008$ & ET KE TA & ER ET KE SO SD TA \\
\hline & $2008 / 2009$ & ER ET KE SD SO SS UG TA & ER ET KE SD SO SS TA \\
\hline & $2009 / 2010$ & BI ER RW SD SO SS UG TA & ER ET SD SO SS TA \\
\hline & $2010 / 2011$ & ER ET KE SD SO SS UG TA & ER ET KE SD SO TA \\
\hline & $2011 / 2012$ & ET SD SS UG TA & ER ET KE SD SO TA \\
\hline & $2012 / 2013$ & ER SD SS TA UG & ER ET SD SS TA \\
\hline & $2013 / 2014$ & KE RW UG TA & KE SD SO TA \\
\hline & $2014 / 2015$ & ER ET KE UG TA & ER ET KE SD SO TA \\
\hline & $2015 / 2016$ & ER ET KE RW SD SO UG & ER ET SD \\
\hline \multirow{16}{*}{$\begin{array}{l}\text { Southern } \\
\text { Africa }\end{array}$} & $2000 / 2001$ & AO & AO NA ZA \\
\hline & $2001 / 2002$ & AO BW SZ ZA ZW & BW MZ NA ZA ZM ZW \\
\hline & $2002 / 2003$ & BW NA SZ ZA ZM ZW & BW NA SZ ZA ZM ZW \\
\hline & $2003 / 2004$ & AO MW SZ & AO BW ZA \\
\hline & $2004 / 2005$ & BW MW MZ ZM ZW & AO BW MW MZ NA ZA ZM ZW \\
\hline & $2005 / 2006$ & & BW MZ ZA \\
\hline & $2006 / 2007$ & BW LS ZA & BW LS MZ NA ZA ZW \\
\hline & $2007 / 2008$ & MG MZ ZW & BW MW MZ ZM ZW \\
\hline & $2008 / 2009$ & MG MZ & MZ ZA ZW \\
\hline & $2009 / 2010$ & AO MZ NA ZA & AO ZA \\
\hline & $2010 / 2011$ & MG MW MZ ZA & MZ ZW \\
\hline & $2011 / 2012$ & AO BW LS MZ ZA ZW & AO BW MZ ZW \\
\hline & $2012 / 2013$ & AO BW MG NA ZM ZW & AO BW MW NA ZA ZM ZW \\
\hline & $2013 / 2014$ & MG MZ ZA ZM & MW MZ ZM ZW \\
\hline & $2014 / 2015$ & AO BW LS MW MZ NA ZA ZM ZW & AO BW LS MW MZ NA SZ ZA ZW \\
\hline & $2015 / 2016$ & AO BW LS MG MW MZ NA SZ ZA ZM ZW & BW LS MZ NA SZ ZA ZW \\
\hline
\end{tabular}

* Country codes: $\mathrm{AO}=$ Angola, $\mathrm{BI}=$ Burundi, $\mathrm{BW}=$ Botswana, $\mathrm{ER}=$ Eritrea, $\mathrm{ET}=$ Ethiopia, $\mathrm{KE}=$ Kenya, $\mathrm{LS}=$ Lesotho, $\mathrm{MG}=$ Madagascar, $\mathrm{MZ}=$ Mozambique, $\mathrm{MW}=$ Malawi, $\mathrm{NA}=$ Namibia, $\mathrm{RW}=\mathrm{Rwanda}$, $\mathrm{SD}=$ Sudan, $\mathrm{SO}=$ Somalia, $\mathrm{SS}=$ South Sudan, $\mathrm{SZ}=$ Swaziland, $\mathrm{TA}=$ Tanzania, $\mathrm{UG}=$ Uganda, $\mathrm{ZA}=$ South Africa, $\mathrm{ZM}=$ Zambia, $\mathrm{ZW}=$ Zimbabwe.

\subsection{Agricultural Droughts during El Niño-Southern Oscillation (ENSO) Events}

The development of agricultural droughts during the two strongest El Niño events and one remarkable La Niña episode registered for the study period is shown in Figures 8-10 for the study regions of southern and eastern Africa, respectively. Here, drought indices SPI-3 and VCI are compared on a monthly scale, where August (Aug) represents conditions during the onset, December (Dec) and January (Jan) is the time of the highest intensity and April (Apr) stands for the declining stage of an ENSO event. These periods were chosen according to their coincidence with major growing seasons over agricultural areas in the focus regions. Hence, areas where site-specific average growing seasons do not coincide with the selected months were excluded from the analyses (dark grey colours in maps). 
In the recent El Niño 2015/2016, which was categorized as a strong event, droughts could be monitored over Ethiopia, Eritrea, Kenya and Uganda showing extensive, severely to extremely dry conditions based on SPI-3 (see Figure 8, August 2015). Further, Sudan was affected moderately. VCI showed a similar pattern with droughts concentrated over Ethiopia, Eritrea, Kenya and Sudan (see Figure 9, August 2015). Though, Uganda was not affected by vegetative droughts. The largest extent of SPI-3-based droughts in southern Africa was recorded in December 2015. At this stage, especially Zambia, Zimbabwe, South Africa, Swaziland and Lesotho were affected by extreme droughts, indicated by SPI-3 below -2 (see Figure 8, December 2015). In the following month, the core zone of drought decreased and moved in north-eastern direction towards Malawi and Mozambique. Monthly means of VCI also indicate extreme drought conditions during the peak of El Niño, with large areas showing VCI values below 20\% (see Figure 9, December 2015 and January 2016). However, VCI exhibits a strikingly smaller drought extent over southern Africa than SPI-3. Here, the zone of drought over Malawi and Mozambique that was revealed from SPI-3, is lacking and drought signals are in fact concentrated over Botswana, South Africa and Lesotho. During the decline of El Niño, droughts were still persistent in southernmost South Africa, Namibia and southern Mozambique according to both drought indices (see Figures 8 and 9, April 2016).
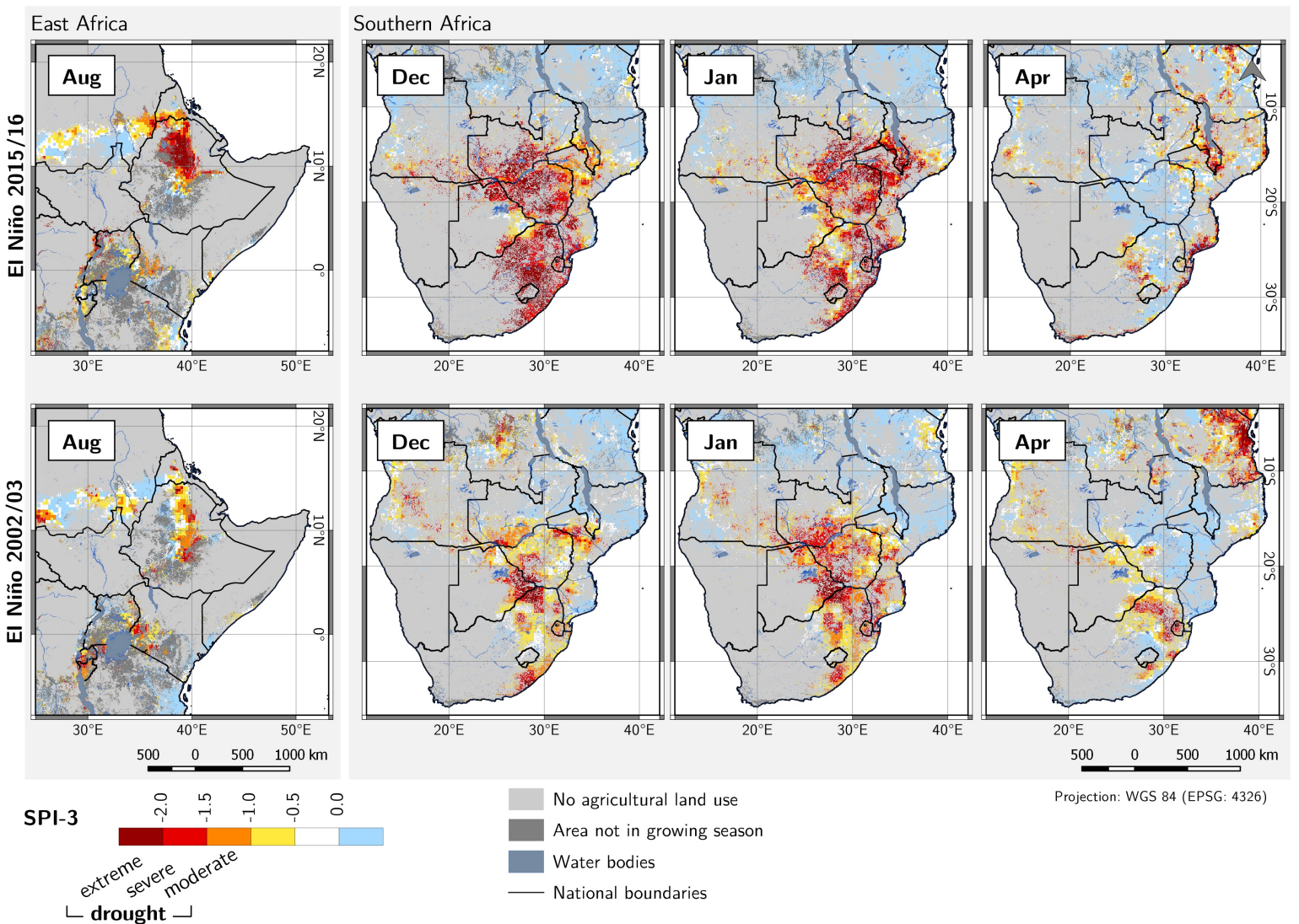

Figure 8. Drought dynamics based on monthly SPI-3 during El Niño events 2015/2016 (strong) and 2002/2003 (moderate) for August (Aug.), December (Dec.), January (Jan.) and April (Apr.) in East and southern Africa. 


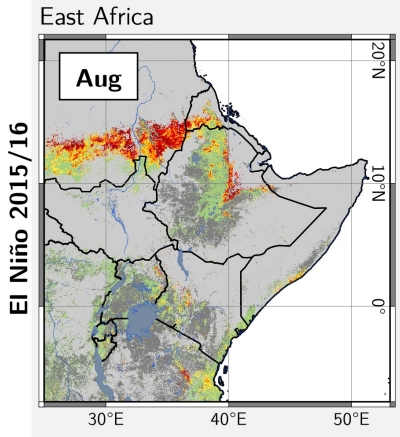

Southern Africa
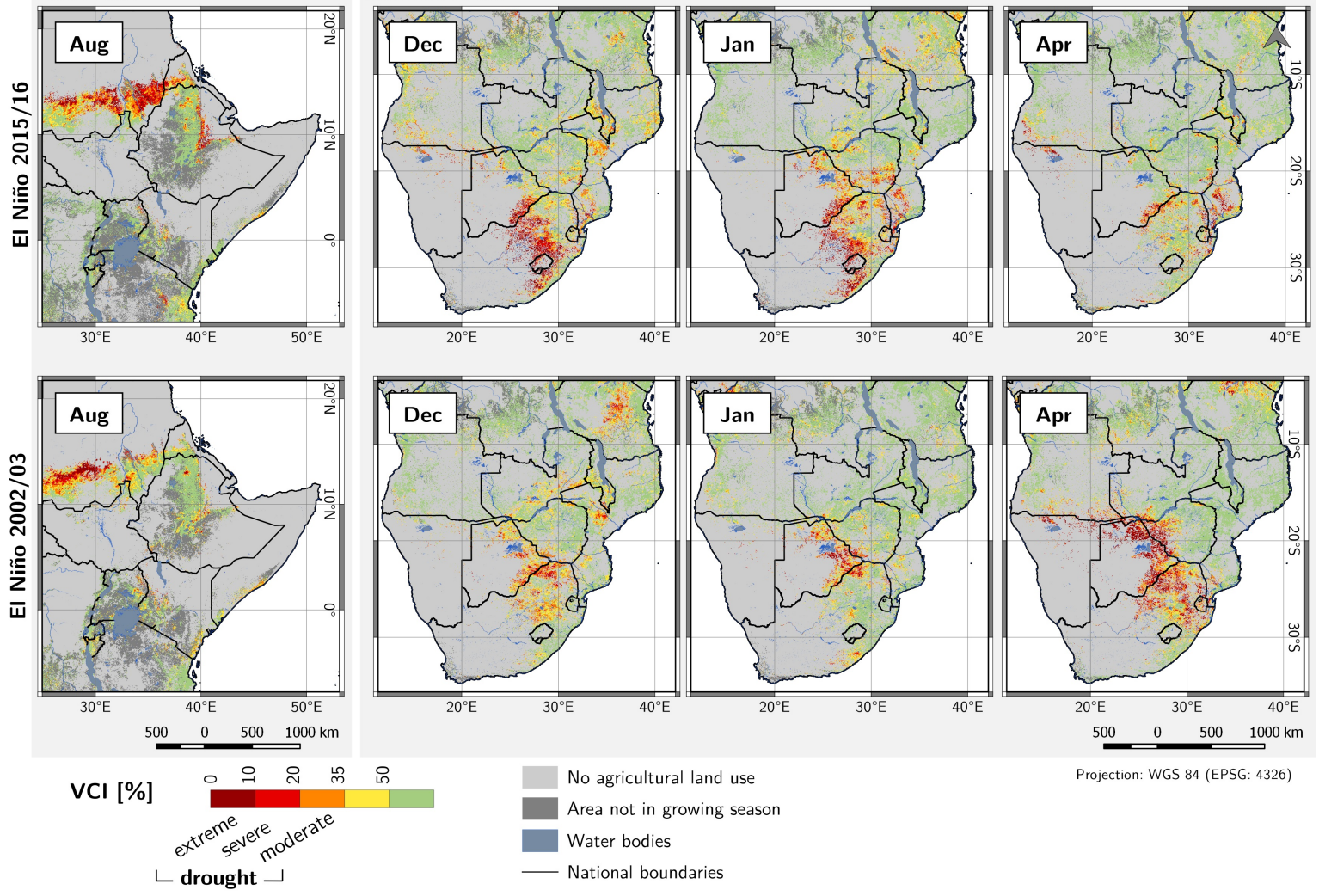

Figure 9. Drought dynamics based on monthly means of VCI during El Niño events 2015/2016 (strong) and 2002/2003 (moderate) for August (Aug.), December (Dec.), January (Jan.) and April (Apr.) in East and southern Africa.

El Niño 2002/2003 exhibits a drought pattern roughly similar to the 2015/2016 situation. First of all, eastern Africa was affected by droughts during the onset of El Niño (see Figures 8 and 9, August 2002). Regarding the phase of high El Niño intensity, a major drought signal could be identified over southern Africa during December and January adapted from both drought indices. Based on SPI-3, drought-affected regions were eastern Botswana and South Africa, Zimbabwe, Lesotho and Swaziland, where dry conditions were particularly emergent during January 2003. VCI-based drought signals were centred over Namibia, Botswana and South Africa, whereas Zimbabwe did not exhibit a noteworthy drought pattern (see Figures 8 and 9, December 2002 and January 2003). Further, a vegetation-based drought signal was still present in the declining stage of El Niño (see Figure 9, April 2003). Thus, compared to SPI-3-based images, the core region of VCI-related droughts was shifted more to the west and showed a higher persistence.

During the onset of moderate La Niña in 2010/2011, a precipitation deficit was observed over central Sudan and southern South Africa (see Figure 10, August 2010). The vegetation-based pattern retraces the SPI-3 drought signal in South Africa, however, indicates merely small spots of drought in Sudan. SPI-3 and VCI reveal a pronounced extensive agricultural drought in eastern Africa during December and January, when La Niña reached its highest intensity. Most affected areas are situated in Ethiopia, Kenya, Uganda and Somalia with extreme SPI-3 values of below -2 and VCI of below 10\% (see Figure 10, December 2010 and January 2011). This extensive eastern African drought showed a high persistence, since even in the declining stage of La Niña, a severe drought signal could be observed from both indicators (see Figure 10, April 2011). 
La Niña 2010/11
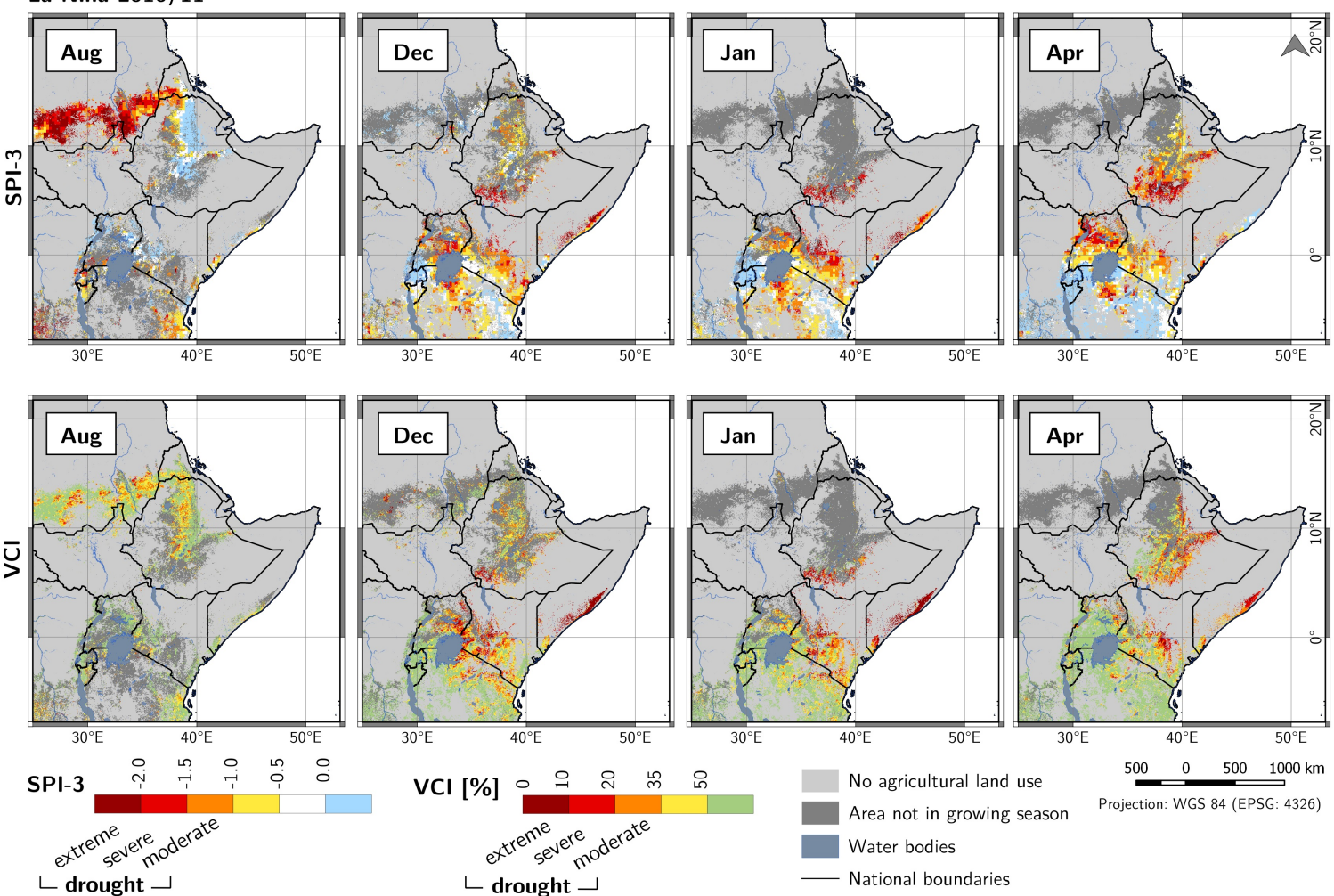

Figure 10. Drought dynamics based on SPI-3 and monthly means of VCI during La Niña event 2010/2011 (moderate) for August (Aug.), December (Dec.), January (Jan.) and April (Apr.) in East Africa.

\subsection{Drought-Affected Cropland and Agricultural Production}

The effects of the particularly severe East African drought in 2010/2011 on cropland and national agricultural production were exemplarily analysed. Hereby, regional drought severity is expressed by means of the relative duration and the spatial extent of agricultural droughts based on VCI thresholds on cropland areas within national and subnational administrative units, respectively (see Figures 11 and 12). Accordingly, regions with most persistent agricultural droughts were Shabeellaha, Banaadir and Galguduud in Somalia with relative drought durations of over $60 \%$ of the growing season period. The border region between Sudan and Eritrea (Al Jazirah and Al Qadarif, Sudan and Gash Barka, Eritrea) exhibit values of over 50\%. Other areas of remarkably high drought persistence (over 30\% of growing seasons affected) can be identified over Sudan, central Kenya and Tanzania.

The extent of agriculturally relevant droughts in eastern Africa during 2010/11 is displayed as pie charts in Figure 12. In total, $88 \%$ of Somalian, $64 \%$ of Sudanian, $41 \%$ of Kenyan and $36 \%$ of Ethiopian cropland areas have been affected by severe to extreme drought conditions with over $30 \%$ of the growing season period showing VCI values of below $35 \%$. In comparison, statistical data of national crop production from the FAOSTAT database [54] are shown in bar diagrams (see Figure 12). Crop production numbers reveal low values for Sudan in 2010, showing a 36\% decline in cereal production. For 2011, however, rather stable crop production values were registered. Since produced crops in Ethiopia have generally been growing from 2000 to 2013, no clear drought impact can be retrieved from the data. Remarkably, statistical data for Somalia indicate a clear break in cereal production for 2011, showing a decrease of $67 \%$ compared to 2010 . Produced cereals came to their lowest value between 2000 and 2013. Since cereals account for a major part of the Somalian crop production, the overall amount of produced crops in Somalia during 2011 represent the minimum of the studied time series. 
A decline in crop production in 2011 can be monitored for Kenya, too. Most notably, vegetable and fruit production decreased about $22 \%$ and $20 \%$ with respect to the previous year. Further, a slight drop $(-7 \%)$ in produced cereals is visible.

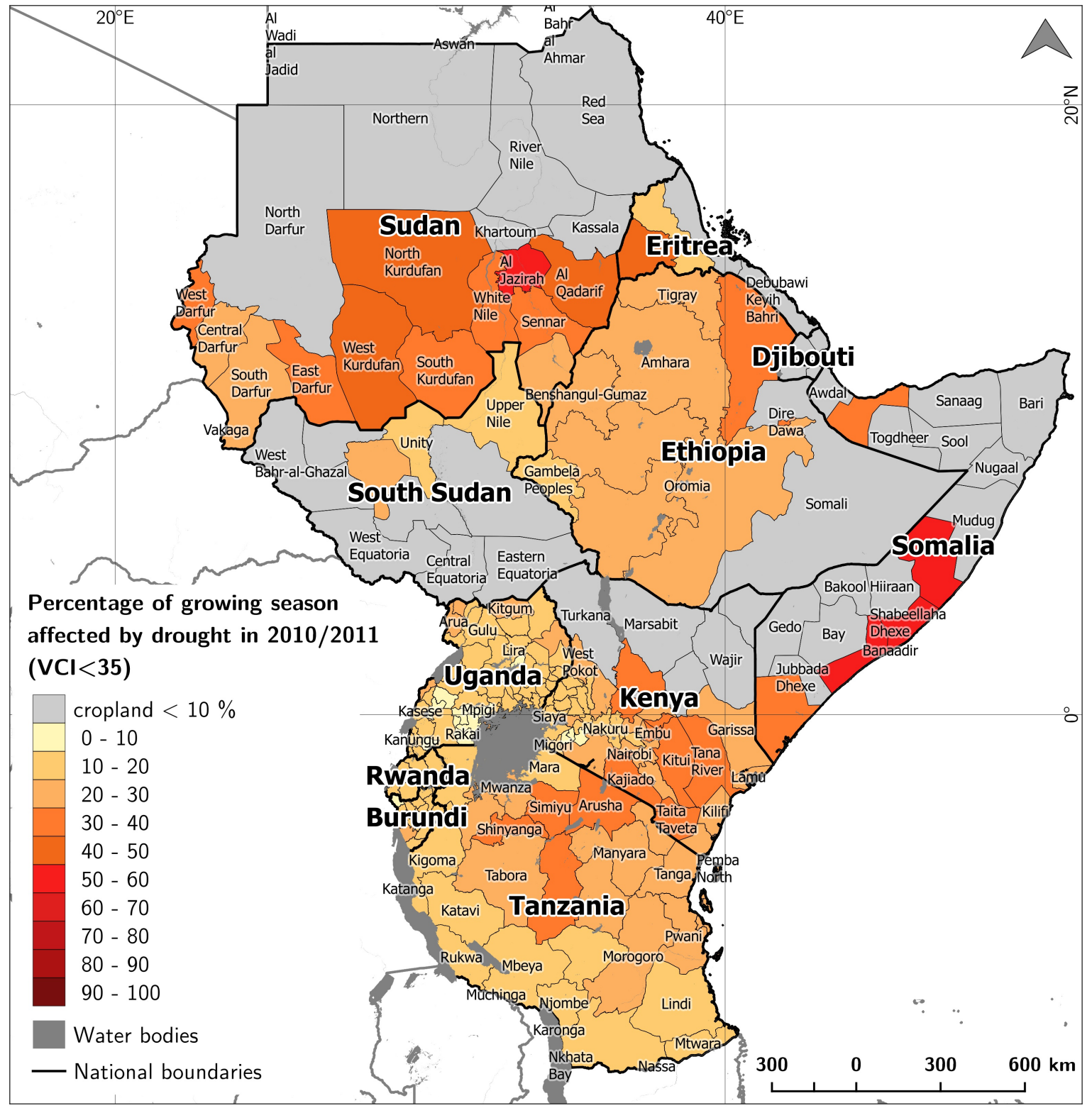

Figure 11. Duration of agriculturally relevant droughts in East African regions during 2010/2011. 


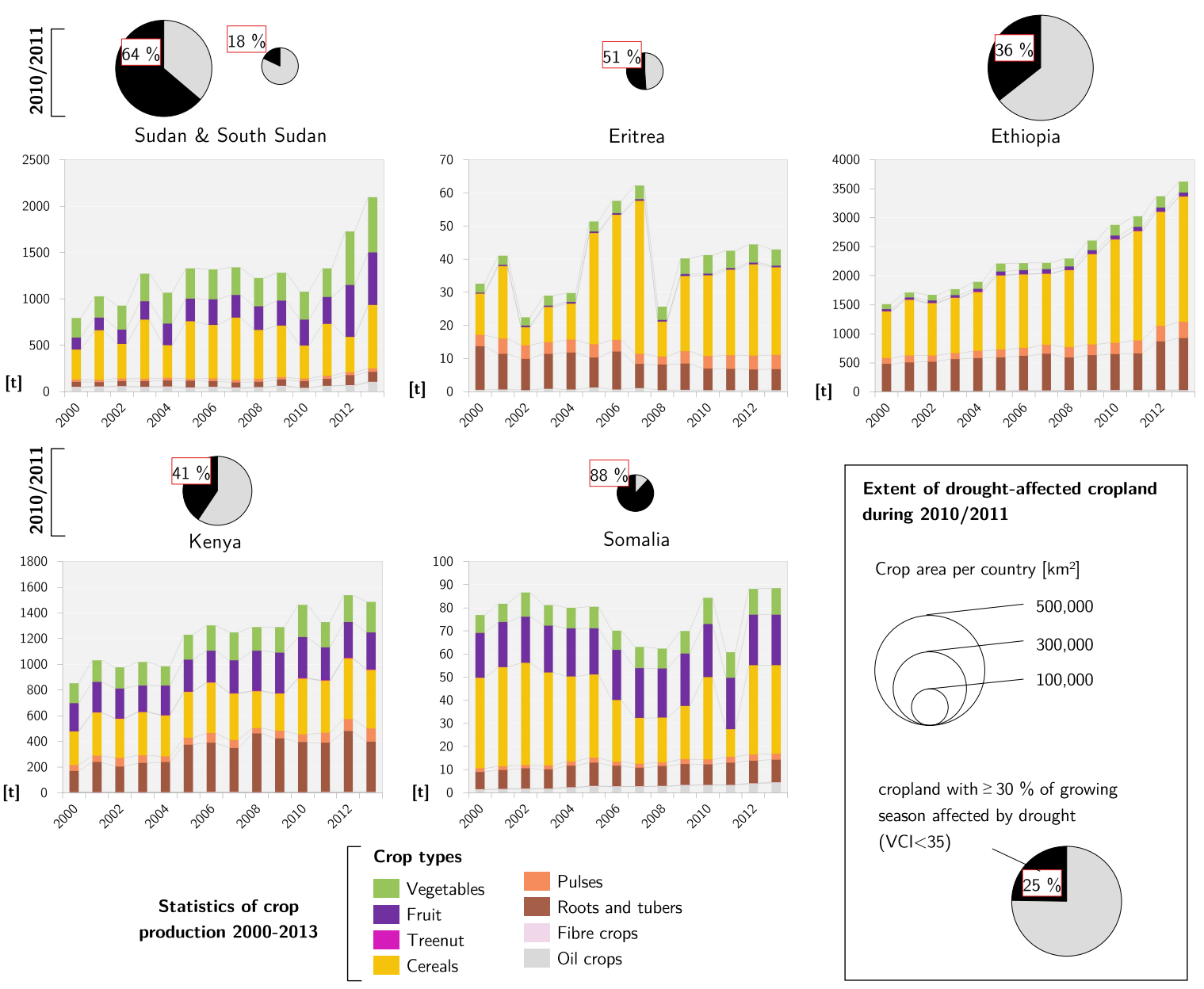

Figure 12. Cropland areas affected by agriculturally relevant droughts in selected East African countries compared with national statistics on annual crop production (Data: FAO [54]).

\section{Discussion}

\subsection{Monitoring Agricultural Droughts over Africa}

The retrospective analysis of agriculturally relevant droughts over Africa shows that major drought events, which are mentioned in literature or registered in the EM-DAT disaster database [8], are largely mirrored in the data. Index-based spatio-temporal drought patterns denote nearly all officially registered drought years between 2000 and 2016 (see Table 4). However, indices uncover a significantly higher amount of agricultural droughts over the selected regions. Here, small-scale drought areas are detected as well. Those may not have led to severe drought effects on a national level and, thus, have not been included in the drought database. For eastern Africa, the precipitation deficit in southeastern Ethiopia during 2009 [60], the extensive vegetative drought over Kenya and Tanzania in 2005/2006 [61] as well as the most striking, severe 2010/2011 drought period that affected large parts of the Horn of Africa, particularly Ethiopia, Kenya and Somalia e.g., [13,24-26], could be identified. Southern African drought events mentioned in literature such as the prolonged and extensive drought in 2002/2003 [29,62], the 2007/2008 drought period in Zimbabwe [27,28] and the 2004/2005 drought in southern Malawi [63] could also be affirmed through the results of our study. 
Table 4. Seasonal years and countries of focal regions affected by extensive droughts according to the EM-DAT disaster database [8]. Framed years are in agreement with revealed SPI-3- and VCI-based results (see Table 3).

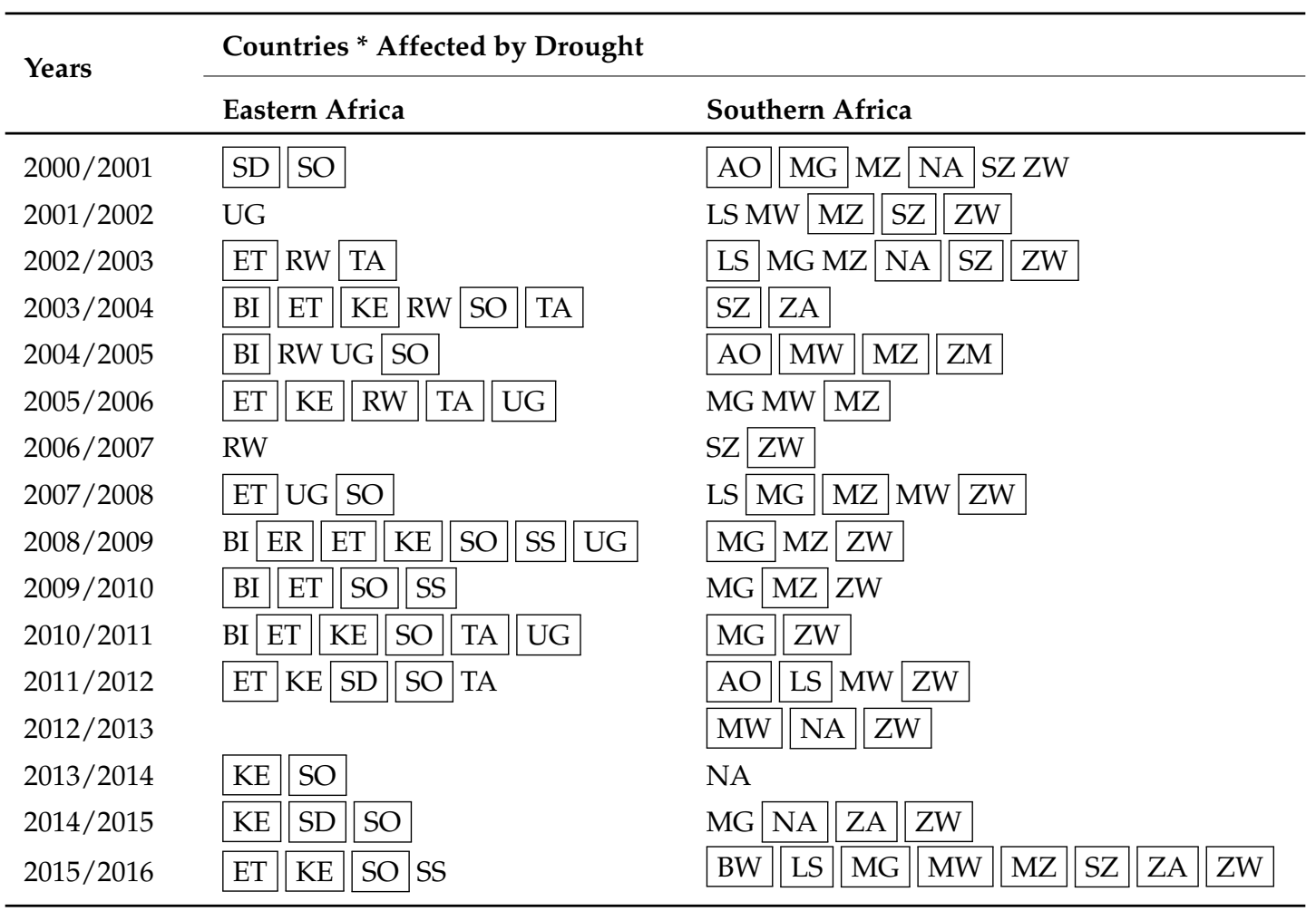

* Country codes: $\mathrm{AO}=$ Angola, $\mathrm{BI}=$ Burundi, $\mathrm{BW}=$ Botswana, $\mathrm{ER}=$ Eritrea, $\mathrm{ET}=$ Ethiopia, $\mathrm{KE}=$ Kenya, LS = Lesotho, $\mathrm{MG}=$ Madagascar, $\mathrm{MZ}=$ Mozambique, $\mathrm{MW}=$ Malawi, NA = Namibia, $\mathrm{RW}=\mathrm{Rwanda}$, $\mathrm{SD}=$ Sudan, $\mathrm{SO}=$ Somalia, $\mathrm{SS}=$ South Sudan, $\mathrm{SZ}=$ Swaziland, $\mathrm{TA}=$ Tanzania, $\mathrm{UG}=$ Uganda, $\mathrm{ZA}=$ South Africa, $\mathrm{ZM}=$ Zambia, $\mathrm{ZW}=$ Zimbabwe.

\subsection{Comparison of SPI-3 and VCI}

Although drought patterns indicated by SPI-3 and VCI agree to a large extent, major deviations could be found for several seasonal years. A striking example is the discrepancies between rainfall-based and vegetation-related drought signals in Zimbabwe, Zambia, Malawi and Mozambique in 2015/2016 (see Figures 8 and 9, maps for December and January 2015/2016). Here, VCI mostly indicates higher vegetation activity than normal, even though pronounced rainfall deficits were observed from SPI-3. On the one hand, these differences can be explained by the particular characteristics of the drought indices themselves. Whereas SPI-3 measures the rainfall deficit from a primarily meteorological point of view, $\mathrm{VCI}$ assesses the condition of the vegetation cover, which is not only influenced by water availability from precipitation but is also affected by human activities in form of agricultural practices (e.g., irrigation, tillage, fertilization), land use changes (e.g., exploitation of natural resources) and by other natural influences such as extreme temperatures, fires, pests or plant diseases. These influencing factors can be equally responsible for variations in NDVI, which provides the basis of VCI [64-66]. Irrigation practices can play a major role for discrepancies between the derived drought signals. According to the Global Map of Irrigation Areas (GMIA) 2005 [67], eastern Africa shows numerous scattered areas of irrigated cropland (see Map A of Figure 13). Further, the high presence of irrigated land area in Malawi can be one of the main causes for the mentioned disaccordance (see Map B of Figure 13). In these areas, the lower reliance of vegetation on rainfall is a possible explanation for the missing match between SPI-based and VCI-based drought severity). 


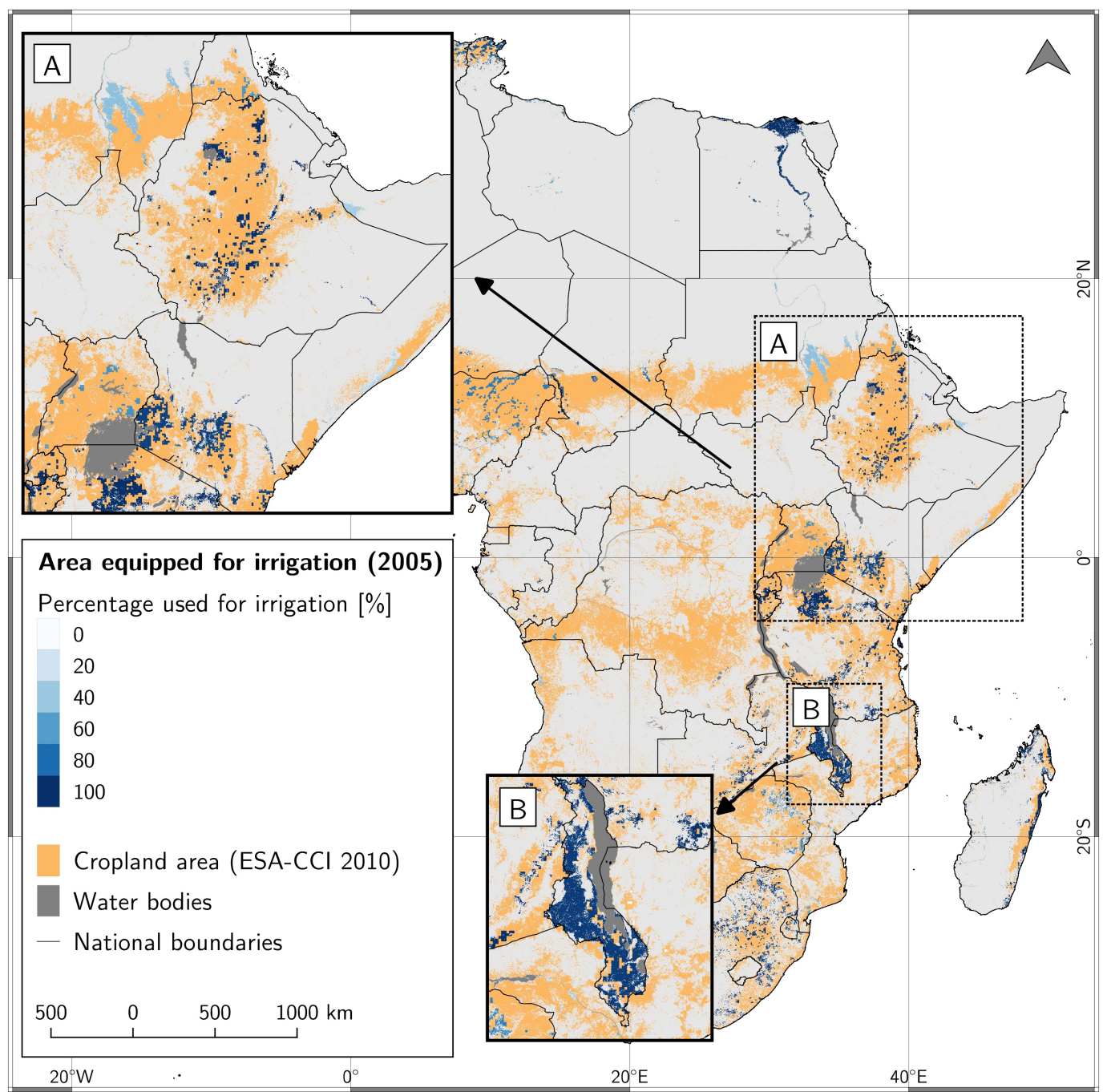

Figure 13. Area of irrigation for selected regions, A: Eastern Africa, B: Malawi (Data: [67]).

In this regard, the effect of temperature on evapotranspiration is worth mentioning, which in turn considerably controls vegetation condition [68]. These aspects, however, are not considered by the SPI. Other potential reasons for deviations between the used drought indices are the accumulated effects of rainfall deficits on vegetation condition and its consecutive delayed response. In this regard, the storage of water in the soil reservoir is an important buffer between rainfall events and soil moisture availability for plants, controlling vegetation condition. The magnitude of this temporal delay depends on vegetation type and characteristics, soil conditions, and potential evapotranspiration [69].

Further, the SPI-3-based rainfall anomalies include events of intense rains that do not necessarily have a positive effect on vegetation condition. Hereby, infiltration to the soil reservoir is minor, since most of the water is lost due to immediate surface run-off [36]. What is more, the timing of rainfall deficits is decisive for the occurrence of vegetative stress and the associated decrease in VCI. Rainfall deficits have different effects depending on their occurrence inside or outside the growing season, but also depending on the phase of the growing season they affect or the specific phenological stage. Although the general timing of the growing season has been accounted for in this study, the crop specific phenological stage, which would have required additional large-scale crop type information, has been neglected. Hence, not all rainfall-derived drought events lead to a pronounced vegetation-based drought signal in the data and, vice versa, not all events of vegetative drought occur as a consequence of a rainfall deficit. 
Another explanation for these deviations is that the sensitivity of vegetation to rainfall is dependent on climate zones, which in turn are controlled by latitudinal bands of mean annual precipitation. Accordingly, areas of arid and semi-arid climate, where water is a limiting factor, show higher sensitivity than more humid subtropical zones [28,69]. Vegetation types and biomes play an important role on land surface response to rainfall variability. Accordingly, areas with shrub- and grassland-dominated vegetation such as savannah systems or cropland exhibit higher sensitivities to rainfall anomalies than tree-dominated vegetation such as forest and woodland systems, which are located in Zambia and central Mozambique (see Figure 1) [69]. Hence, the vegetation type might be one of the reasons for the differing drought patterns in these areas.

\subsection{Spatio-Temporal Variability of Agricultural Droughts during ENSO Events}

By comparing the African rainfall anomalies and vegetation condition for selected months (see Figures 8-10), drought conditions during El Niño events were observed over southern Africa, which agrees with observations from numerous scientific studies e.g., [9,27,33,70,71]. Eastern African rainfall anomalies and vegetation are sensitive to ENSO during both first growing seasons (Ethiopian "meher", Somalian "deyr" and Kenyan "short rains" from October to December) and the early second growing seasons (Ethiopian "belg", Somalian "gu" and Kenyan "long rains" from February to May) over areas with bimodal rainfall cycles (compare also Figure 3). This was revealed from observed droughts during La Niña phases that coincide with respective growing seasons (see Figure 10). However, Philippon et al. [36] suggested a remarkably weaker effect of ENSO for the secondary, compared to the first growing season, based on long-term analysis of NDVI and its sensitivity to ENSO. In the present study, drought signals were observed over central Ethiopia, Uganda and western Kenya in the ongoing stage of El Niño, prior to the phase of highest ENSO intensity (see Figures 8 and 9). These findings can be confirmed by Philippon et al. [36], who identified negative correlations between NDVI and ENSO for August to November during the onset of El Niño. This in turn could directly be connected to preceding rainfall deficits during the rainy season from June to September [72,73]. Further, these negatively related areas mainly coincide with zones of intense agricultural production [36]. Thus, it can be stated that drought response to ENSO is dependent on the climate zone and the corresponding rainfall regime in eastern Africa. In this regard, areas showing a bimodal rainfall cycle are more prone to droughts during La Niña, whereas regions with unimodal rainfall distribution exhibit drier conditions in the onset stage of El Niño [1].

The multi-annual analysis further shows that each El Niño and La Niña event leads to different drought patterns. Based on the findings of Ropelewski and Halpert [74] and further studies investigating the major effects of ENSO on temperature and precipitation around the globe, e.g., [75,76], dry conditions over southeastern Africa are frequently identified during El Niño events, whereas the southern part of eastern Africa shows a drying pattern during the peak phase of La Niña. Thus, although this typical continental-scale teleconnection pattern could broadly be confirmed from observations of the present study, no universal ENSO-induced drought effect could be derived for the African continent, since every event shows its distinct spatio-temporal drought response pattern. Accordingly, not every El Niño causes severe drought conditions over southern Africa (as during El Niño 2002/2003 and 2015/2016), which could be seen in the case of 2009/2010. Likewise, droughts in Kenya and Somalia during La Niña are not always as pronounced and extensive as in 2010/2011.

Recently, an important influencing factor for the differing effects of ENSO on drought patterns has been discussed in the scientific community, which involves different ENSO variants $[73,77,78]$. The so-called "Modoki" type of ENSO differs from the conventional canonical ENSO variant in its signature of SST anomalies over the equatorial Pacific. In this context, El Niño (La Niña) Modoki is associated with an anomalous warming (cooling) of sea surface temperatures in the central Pacific, in contrast to the canonical event that corresponds to the eastern Pacific [73]. Both Manatsa et al. [77] and Ratnam et al. [78] mention the weak effect of ENSO on precipitation anomalies over southern Africa during the 2009/2010 El Niño that was identified as a Modoki event. Accordingly, heat-induced 
tropical circulation and tropospheric stationary wave responses are different for Modoki events, which may lead to suppressed negative rainfall anomalies over southern Africa. This might be a possible reason for the revealed poor agreement between 2009/2010 and the other studied El Niño events (compare maps of respective seasonal years in Figures 4-7).

What is more, each ENSO event must be put in relation with its large-scale chronology. In this regard, Rojas et al. [79] identified temporal cycles in the order of several years in which the influence of one ENSO phase overbalances the other. Accordingly, the effects of ENSO events differ if either El Niño or La Niña years predominate the corresponding temporal cycle. Thus, an El Niño year taking place during a cycle of La Niña dominance, as it was the case during 2009/2010, shows lower drought impacts on agricultural areas than anticipated from previous events being related to El Niño dominance cycles. In contrast, La Niña events taking place during the dominance of El Niño are attributed to bring about extended agricultural droughts [79]. It was observed that vegetation-based drought response showed particularly high cumulative effects when La Niña years followed after pronounced El Niño episodes, e.g., 1999/2000 revealed from [34], which was the case for La Niña 2010/2011.

\subsection{Potential and Limitations}

As demonstrated in this study, a comprehensive insight into the spatio-temporal dynamics of large-scale drought patterns can be gained by means of the analysis of remote sensing-based drought indices. On the one hand, the applied methodology yields promising results, providing the basis for potential further research. On the other hand, it has to be considered that the used approach holds certain limitations. As a first constraint, the availability of MODIS data (from February/March 2000) accounts for the relatively short study period, which limits the significance of statistical analysis forming the basis for the used drought indices. However, other comparable data sets, e.g., SPOT-VGT or Proba-V, do not provide a longer temporal coverage either $[80,81]$. As an alternative, AVHRR data offers a long image record beginning in the early 1980s. However, AVHRR data over Africa are only available at course spatial resolutions of $1 \mathrm{~km}$ and even $8 \mathrm{~km}$ for NDVI in a consistently processed database [82]. This limits its application for drought monitoring, particularly when considering the relatively small-scaled agriculture of Africa. Other restrictions originate from the limitations of remotely sensed data used in this study. The TRMM data set, which was used for calculating the SPI, includes uncertainties that lead to errors in rainfall estimates. For Africa, uncertainties are mainly related to areas with complex topography or humid climate [31,83]. Further, calculations of VCI are based on NDVI as an index for vegetation vigour. However, NDVI holds certain limitations, too. As an example, the sensitivity of NDVI to soil moisture and colour leads to soil-related effects on NDVI over sparsely vegetated areas. Other weaknesses of NDVI are its tendency of saturation in densely vegetated areas as well as observed atmospheric interferences related to aerosols and cloud cover [16]. However, the used data and applied indices are broadly approved within the scientific community and are among the most fitting available instruments for remote sensing-based drought assessment over large areas.

In order to test for the quality of the presented drought index- and growing season-based approach of continental drought monitoring, an accurate validation would be necessary. For this purpose, detailed statistics on agricultural yields, sampled ground truth data or measured rainfall anomalies would be required, which however were not available at continental scale for this study. Validation and an uncertainty analysis remain outstanding issues, which could possibly be assessed in a larger study framework. Furthermore, for examining the relation between ENSO and agriculturally relevant droughts over Africa in more depths, additional influencing factors such as temperature, evapotranspiration, soil properties and crop types could be considered. Multiple regression analyses and testing for non-linear relations are suggested in order to quantify the connection between ENSO and rainfall deficits.

Nevertheless, we proved the applicability of SPI-3 and VCI for monitoring agriculturally relevant droughts on a continental scale. A huge amount of drought-related data sets were processed and 
newly generated for the whole African continent. Furthermore, the usage of two different drought indices illuminated both rainfall as the main trigger and vegetation as a land surface response to drought. Therefore, agriculturally relevant droughts could be assessed from two complementary perspectives. The special value of this study is its exclusive focus on agricultural areas and its consideration of the timing of site-specific growing seasons assessing droughts relevant for agricultural production. Such knowledge is crucial and forms the basis for implementing strategies of drought hazard mitigation. Farmers of drought-prone regions could adapt their agricultural practices by using drought-resistant crop varieties or implementing sustainable irrigation applications. The prediction of future droughts depends on accurate retrospective monitoring and becomes increasingly important for taking measures to reduce the impacts of severe droughts on society. On this basis, precautions could be made by local authorities and timely humanitarian aid can be given to drought-affected regions in case of extensive crop failures and food shortage.

\section{Conclusions}

In this study, we examined the spatio-temporal evolution of droughts affecting agriculture in Africa and their connection to ENSO events during the last 16 years by applying two different drought indices. Based on remotely sensed rainfall anomalies (SPI-3) and surface reflectance data related to vegetation condition (VCI), large-scale patterns of agriculturally relevant droughts could be identified. For eastern Africa, 2009 and 2011 could be revealed as major drought years, whereas southern Africa was affected by particularly severe agriculturally relevant droughts in 2003 and $2015 / 2016$. Additionally, numerous regional-scale dry episodes could be detected. The findings are in broad accordance with major recorded drought events. We proved the applicability of SPI-3 and VCI as indices for a comprehensive continental-scale monitoring of agriculturally relevant droughts. Differences between the drought signals derived from each of the used indices could be explained by the complex relationship between rainfall anomalies and vegetation condition, which by itself is influenced by multiple environmental parameters and land use practices such as irrigation.

The tendency of drought occurrence during El Niño could be observed over large parts of southern Africa. In contrast, eastern Africa exhibits an east-west dipole pattern: Zones with two major growing seasons tend to respond to droughts caused by La Niña events. In contrast, we revealed drought tendencies during the onset of El Niño for areas with a single growing season. By studying drought patterns for each of the major ENSO events from 2000 to 2016, it could be concluded that every El Niño and La Niña episode shows its distinct signal of rainfall- and vegetation-related droughts. In this context, the effect of different ENSO variants as well as multi-year cycles with either El Niño or La Niña dominance were discussed as possible influencing factors.

Overcoming the methodological limitations of the study, a comprehensive validation and the assessment of uncertainties would be required. However, adequate reference data sources are scarce and have to be considered in a larger framework. All in all, a comprehensive insight into spatio-temporal drought dynamics was gained through this study by providing a complementary perspective on agricultural droughts based on both rainfall and vegetation condition. Above all, the exclusive consideration of average site-specific growing seasons and agricultural areas is the unique feature of the study. Moreover, we illustrated the relationship between ENSO events and drought evolution over Africa in its fundamentals. This is regarded as essential for a better understanding of the interconnections between global climate oscillations and rainfall anomalies leading to droughts in Africa. The opportunities of drought monitoring using advanced remote sensing techniques and the increased availability of earth observation data will likely continue to contribute and to build up a solid knowledge base related to droughts in African agricultural areas. Altogether, this lays the foundation for decision making and capacity building to mitigate the effects of severe droughts and adapt to existent drought hazards.

Acknowledgments: We would like to thank Marine Locquet who contributed to the time series processing by supporting the extraction of phenological parameters. 
Author Contributions: Karina Winkler conducted the processing of the time series and the derivation of drought parameters and together with Ursula Gessner conceived and conducted the analyses of the results; Volker Hochschild supervised the preceding master thesis and guided the progress of the study. Karina Winkler wrote the first version of the manuscript and all authors jointly improved the version based on critical discussion.

Conflicts of Interest: The authors declare no conflict of interest.

\section{References}

1. Schubert, S.D.; Stewart, R.E.; Wang, H.; Barlow, M.; Berbery, E.H.; Cai, W.; Hoerling, M.P.; Kanikicharla, K.K.; Koster, R.D.; Lyon, B.; et al. Global meteorological drought: A synthesis of current understanding with a focus on sst drivers of precipitation deficits. J. Clim. 2016, 29, 3989-4019.

2. Van Loon, A.F. Hydrological drought explained. Wiley Interdiscip. Rev. Water 2015, 2, 359-392.

3. Dai, A. Drought under global warming: A review. Wiley Interdiscip. Rev. Clim. Chang. 2011, 2, $45-65$.

4. Masih, I.; Maskey, S.; Mussá, F.E.F.; Trambauer, P. A review of droughts on the African continent: A geospatial and long-term perspective. Hydrol. Earth Syst. Sci. 2014, 18, 3635-3649.

5. Jaramillo, F.; Destouni, G. Local flow regulation and irrigation raise global human water consumption and footprint. Science 2015, 350, 1248-1251.

6. Hao, Z.; AghaKouchak, A.; Nakhjiri, N.; Farahmand, A. Global integrated drought monitoring and prediction system. Sci. Data 2014, 1, doi:10.1038/sdata.2014.1.

7. Rosenzweig, C.; Hillel, D. Climate Variability and the Global Harvest: Impacts of El Niño and Other Oscillations on Agroecosystems; Oxford University Press: New York, NY, USA, 2008.

8. Guha-Sapir, D.; Below, R.; Hoyois, P. EM-DAT: The CRED/OFDA International Disaster Database, Université Catholique de Louvain, 2016. Available online: www.emdat.be (accessed on 2 November 2016).

9. Propastin, P.; Fotso, L.; Kappas, M. Assessment of vegetation vulnerability to ENSO warm events over Africa. Int. J. Appl. Earth Obs. Geoinf. 2010, 12S, S83-S89.

10. Food and Agriculture Organization of the United Nations (FAO). El Niño Set to Have a Devastating Impact on Southern Africa's Harvests and Food Security. Joint Statement by FAO, EC-JRC, FEWS NET and WFP, 2016. Available online: http:/ / www.fao.org/news/story/en/item/382932/icode/ (accessed on 10 January 2017).

11. Naumann, G.; Dutra, E.; Barbosa, P.; Pappenberger, F.; Wetterhall, F.; Vogt, J.V. Comparison of drought indicators derived from multiple data sets over Africa. Hydrol. Earth Syst. Sci. 2014, 18, 1625-1640.

12. Rojas, O.; Vrieling, A.; Rembold, F. Assessing drought probability for agricultural areas in Africa with coarse resolution remote sensing imagery. Remote Sens. Environ. 2011, 115, 343-352.

13. Meroni, M.; Verstraete, M.M.; Rembold, F.; Urbano, F.; Kayitakire, F. A phenology-based method to derive biomass production anomalies for food security monitoring in the Horn of Africa. Int. J. Remote Sens. 2014, 35, 2472-2492.

14. Eerens, H.; Haesen, D.; Rembold, F.; Urbano, F.; Tote, C.; Bydekerke, L. Image time series processing for agriculture monitoring. Environ. Model. Softw. 2014, 53, 154-162.

15. Steinemann, A.C.; Hayes, M.J.; Cavalcanti, L.F. Drought Indicators and Triggers. In Drought and Water Crises: Science, Technology, and Management Issues; Wilhite, D.A., Ed.; Taylor \& Francis: Boca Raton, FL, USA, 2005; Chapter 4, pp. 71-92.

16. Zargar, A.; Sadiq, R.; Naser, B.; Khan, F.I. A review of drought indices. Environ. Rev. 2011, 19, 333-349.

17. Svoboda, M.; LeComte, D.; Hayes, M.; Heim, R.; Gleason, K.; Angel, J.; Rippey, B.; Tinker, R.; Palecki, M.; Stooksbury, D.; et al. The drought monitor. Bull. Am. Meteorol. Soc. 2002, 83, 1181-1190.

18. Deng, M.X.; Di, L.P.; Han, W.G.; Yagci, A.L.; Peng, C.M.; Heo, G. Web-service-based Monitoring and Analysis of Global Agricultural Drought. Photogramm. Eng. Remote Sens. 2013, 79, 929-943.

19. Senay, G.B.; Velpuri, N.M.; Bohms, S.; Budde, M.; Young, C.; Rowland, J.; Verdin, J.P. Drought Monitoring and Assessment : Remote Sensing and Modeling Approaches for the Famine Early Warning Systems Network. Hydro-Meteorol. Hazards Risks Disasters 2015, 233-262, doi:10.1016/B978-0-12-394846-5.00009-6.

20. Sheffield, J.; Wood, E.F.; Chaney, N.; Guan, K.; Sadri, S.; Yuan, X.; Olang, L.; Amani, A.; Ali, A.; Demuth, S.; et al. A drought monitoring and forecasting system for sub-sahara african water resources and food security. Bull. Am. Meteorol. Soc. 2014, 95, 861-882.

21. Knauer, K.; Gessner, U.; Dech, S.; Kuenzer, C. Remote sensing of vegetation dynamics in West Africa. Int. J. Remote Sens. 2014, 35, 6357-6396. 
22. Karlson, M.; Ostwald, M. Remote sensing of vegetation in the Sudano-Sahelian zone: A literature review from 1975 to 2014. J. Arid Environ. 2016, 124, 257-269.

23. Mbow, C.; Brandt, M.; Ouedraogo, I.; de Leeuw, J.; Marshall, M. What four decades of earth observation tell us about land degradation in the Sahel? Remote Sens. 2015, 7, 4048-4067.

24. Anderson, W.B.; Zaitchik, B.F.; Hain, C.R.; Anderson, M.C.; Yilmaz, M.T.; Mecikalski, J.; Schultz, L. Towards an integrated soil moisture drought monitor for East Africa. Hydrol. Earth Syst. Sci. 2012, 16, 2893-2913.

25. AghaKouchak, A. A multivariate approach for persistence-based drought prediction: Application to the 2010-2011 East Africa drought. J. Hydrol. 2015, 526, 127-135.

26. Dutra, E.; Magnusson, L.; Wetterhall, F.; Cloke, H.L.; Balsamo, G.; Boussetta, S.; Pappenberger, F. The 2010-2011 drought in the Horn of Africa in ECMWF reanalysis and seasonal forecast products. Int. J. Climatol. 2013, 33, 1720-1729.

27. Brown, M.E.; Funk, C.C. Early Warning of Food Security Crises in Urban Areas: The Case of Harare, Zimbabwe, 2007. In Geospatial Techniques in Urban Hazard and Disaster Analysis; Springer: Dordrecht, The Netherlands; New York, NY, USA, 2010; pp. 229-241.

28. Mutowo, G.; Chikodzi, D. Remote sensing based drought monitoring in Zimbabwe. Disaster Prev. Manag. 2014, 23, 549-659.

29. Rouault, M.; Richard, Y. Intensity and spatial extent of droughts in southern Africa. Geophys. Res. Lett. 2005, $32,2-5$.

30. Chisadza, B.; Tumbare, M.J.; Nyabeze, W.R.; Nhapi, I. Linkages between local knowledge drought forecasting indicators and scientific drought forecasting parameters in the Limpopo River Basin in Southern Africa. Int. J. Disaster Risk Reduct. 2015, 12, 226-233.

31. Naumann, G.; Barbosa, P.; Carrao, H.; Singleton, A.; Vogt, J. Monitoring drought conditions and their uncertainties in Africa using TRMM data. J. Appl. Meteorol. Climatol. 2012, 51, 1867-1874.

32. Vicente-Serrano, S.M.; Cabello, D.; Tomás-Burguera, M.; Martín-Hernández, N.; Beguería, S.; Azorin-Molina, C.; Kenawy, A.E. Drought variability and land degradation in semiarid regions: Assessment using remote sensing data and drought indices (1982-2011). Remote Sens. 2015, 7, 4391-4423.

33. Meque, A.; Abiodun, B.J. Simulating the link between ENSO and summer drought in Southern Africa using regional climate models. Clim. Dyn. 2015, 44, 1881-1900.

34. Anyamba, A.; Tucker, C.J.; Mahoney, R. From El Niño to La Niña: Vegetation response patterns over east and southern Africa during the 1997-2000 period. J. Clim. 2002, 15, 3096.

35. Crétat, J.; Richard, Y.; Pohl, B.; Rouault, M.; Reason, C.; Fauchereau, N. Recurrent daily rainfall patterns over South Africa and associated dynamics during the core of the austral summer. Int. J. Climatol. 2012, 32, 261-273.

36. Philippon, N.; Martiny, N.; Camberlin, P.; Hoffman, M.T.; Gond, V. Timing and patterns of the ENSO signal in Africa over the last 30 years: Insights from Normalized Difference Vegetation Index Data. J. Clim. 2014, 27, 2509-2532.

37. Jones, A.; Breuning-Madsen, H.; Brossard, M.; Dampha, A.; Deckers, J.; Dewitte, O.; Gallali, T.; Hallett, S.; Jones, R.; Kilasara, M.; et al. Soil Atlas of Africa; Publications Office of the European Union: Luxembourg, 2013.

38. Peel, M.C.; Finlayson, B.L.; McMahon, T.A. Updated world map of the Köppen-Geiger climate classification. Meteorol. Z. 2007, 15, 259-263.

39. UNEP. Africa: Atlas of Our Changing Environment; United Nations Environment Programme: Nairobi, Kenya, 2008.

40. European Space Agency (ESA) CCI Land Cover. Land Cover Maps: Three Global LC Maps for the 2000, 2005 and 2010 Epochs, 2014. Available online: https:/ / www.esa-landcover-cci.org/?q=node/158 (accessed on 16 March 2017).

41. Vermote, E. MOD09A1 MODIS/Terra Surface Reflectance 8-Day L3 Global 500 m SIN Grid V006. NASA EOSDIS Land Processes DAAC, 2015. Available online: https://lpdaac.usgs.gov/node/804 (accessed on 6 August 2016).

42. Tucker, C.J. Red and photographic infrared linear combinations for monitoring vegetation. Remote Sens. Environ. 1979, 8, 127-150.

43. Kogan, F.N. Remote sensing of weather impacts on vegetation in non-homogeneous areas. Int. J. Remote Sens. 1990, 11, 1405-1419.

44. Kogan, F.; Sullivan, J. Development of global drought-watch system using NOAA/AVHRR data. Adv. Space Res. 1993, 13, 219-222. 
45. Thenkabail, P.S.; Gamage, M.S.D.N.; Smakhtin, V.U. The Use of Remote-Sensing Data for Drought Assessment and Monitoring in Southwest Asia. Int. Water Manag. Inst. Res. Rep. 2004, 85, 1-22.

46. Unganai, L.S.; Kogan, F.N. Drought Monitoring and Corn Yield Estimation in Southern Africa from AVHRR Data. Remote Sens. Environ. 1998, 63, 219-232.

47. McKee, T.B.; Doesken, N.J.; Kleist, J. The relationship of drought frequency and duration to time scales. In Proceedings of the AMS 8th Conference on Applied Climatology, Anaheim, CA, USA, 17-22 January 1993; pp. 179-184.

48. Huffman, G.J.; Bolvin, D.T.; Nelkin, E.J.; Wolff, D.B.; Adler, R.F.; Gu, G.; Hong, Y.; Bowman, K.P.; Stocker, E.F. The TRMM Multisatellite Precipitation Analysis (TMPA): Quasi-Global, Multiyear, Combined-Sensor Precipitation Estimates at Fine Scales. J. Hydrometeorol. 2007, 8, 38-55.

49. Tropical Rainfall Measuring Mission (TRMM). TRMM (TMPA/3B43) Rainfall Estimate L3 1 Month 0.25 Degree $\times$ 0.25 Degree V7, Greenbelt, MD, Goddard Earth Sciences Data and Information Services Center (GES DISC), 2011. Available online: http:/ / disc.gsfc.nasa.gov / datacollection/TRMM_3B43_7.html (accessed on 6 August 2016).

50. World Meteorologic Organization (WMO). Standardized Precipitation Index User Guide; Svoboda, M., Hayes, M., Wood, D., Eds.; WMO-No. 1090; WMO: Geneva, Switzerland, 2012.

51. Keyantash, J.; National Center for Atmospheric Research Staff . The Climate Data Guide: Standardized Precipitation Index (SPI), 2016. Available online: https://climatedataguide.ucar.edu/climate-data/ standardized-precipitation-index-spi (accessed on 19 November 2016).

52. Asadi Zarch, M.A.; Sivakumar, B.; Sharma, A. Droughts in a warming climate: A global assessment of Standardized precipitation index (SPI) and Reconnaissance drought index (RDI). J. Hydrol. 2015, 526, 183-195.

53. R Core Team. R: A Language and Environment for Statistical Computing; R Foundation for Statistical Computing: Vienna, Austria, 2013. Available online: https:/ / www.R-project.org (accessed on 8 November 2016).

54. Food and Agriculture Organization of the United Nations (FAO). Food and Agriculture Organization Corporate Statistical Database (FAOSTAT): Crop Statistics. 2016. Available online: http:/ /www.fao.org/ faostat/en/\#data (accessed on 29 October 2016).

55. Eklundh, L.; Jönsson, P. TIMESAT: A Software Package for Time-Series Processing and Assessment of Vegetation Dynamics. In Remote Sensing Time Series; Kuenzer, C., Dech, S., Wagner, W., Eds.; Springer: Cham, Switzerland, 2015; Chapter 7, pp. 141-158.

56. Savitzky, A.; Golay, M.J.E. Smoothing and Differentiation of Data by Simplified Least Squares Procedures. Anal. Chem. 1964, 36, 1627-1639.

57. Kogan, F.N. Application of vegetation index and brightness temperature for drought detection. Adv. Space Res. 1995, 15, 91-100.

58. Gebrehiwot, T.; Veen, A.V.D.; Maathuis, B. Spatial and temporal assessment of drought in the Northern highlands of Ethiopia. Int. J. Appl. Earth Obs. Geoinf. 2011, 13, 309-321.

59. Klisch, A.; Atzberger, C. Operational drought monitoring in Kenya using MODIS NDVI time series. Remote Sens. 2016, 8, 267.

60. Viste, E.; Korecha, D.; Sorteberg, A. Recent drought and precipitation tendencies in Ethiopia. Theor. Appl. Climatol. 2013, 112, 535-551.

61. Rulinda, C.M.; Dilo, A.; Bijker, W.; Stein, A. Characterising and quantifying vegetative drought in East Africa using fuzzy modelling and NDVI data. J. Arid Environ. 2012, 78, 169-178.

62. Mussá, F.E.F.; Zhou, Y.; Maskey, S.; Masih, I.; Uhlenbrook, S. Groundwater as an emergency source for drought mitigation in the Crocodile River catchment, South Africa. Hydrol. Earth Syst. Sci. 2015, 19, 1093-1106.

63. Jayanthi, H.; Husak, G.J.; Funk, C.; Magadzire, T.; Chavula, A.; Verdin, J.P. Modeling rain-fed maize vulnerability to droughts using the standardized precipitation index from satellite estimated rainfallamp-Southern Malawi case study. Int. J. Disaster Risk Reduct. 2013, 4, 71-81.

64. Du, L.; Tian, Q.; Yu, T.; Meng, Q.; Jancso, T.; Udvardy, P.; Huang, Y. A comprehensive drought monitoring method integrating MODIS and TRMM data. Int. J. Appl. Earth Obs. Geoinf. 2013, 23, 245-253.

65. Herrmann, S.M.; Anyamba, A.; Tucker, C.J. Recent trends in vegetation dynamics in the African Sahel and their relationship to climate. Glob. Environ. Chang. 2005, 15, 394-404.

66. Sepulcre-Canto, G.; Horion, S.; Singleton, A.; Carrao, H.; Vogt, J. Development of a Combined Drought Indicator to detect agricultural drought in Europe. Nat. Hazards Earth Syst. Sci. 2012, 12, 3519-3531. 
67. Siebert, S.; Henrich, V.; Frenken, K.; Burke, J. Global Map of Irrigation Areas Version 5, 2013. Rheinische Friedrich-Wilhelms-University, Bonn, Germany/Food and Agriculture Organization of the United Nations, Rome, Italy. Available online: http://www.fao.org/nr/water/aquastat/irrigationmap/ (accessed on 25 July 2017).

68. Hayes, M.J.; Svoboda, M.D.; Wardlow, B.D.; Anderson, M.C.; Kogan, F. Drought Monitoring Historical and Current Perspectives. In Remote Sensing of Drought: Innovative Monitoring Approaches; Wardlow, B.D., Anderson, M.C., Verdin, J.P., Eds.; CRC Press: Boca Raton, FL, USA, 2012; Chapter 1, pp. 1-19.

69. Hawinkel, P.; Thiery, W.; Lhermitte, S.; Swinnen, E.; Verbist, B.; Van Orshoven, J.; Muys, B. Vegetation response to precipitation variability in East Africa controlled by biogeographical factors. J. Geophys. Res. Biogeosci. 2016, $121,2422-2444$.

70. Niang, I.; Ruppel, M.A.; Abdrabo, A.; Essel, C.; Lennard, J.; Padgham, J.; Urquhart, P. Africa. Climate Change 2014: Impacts, Adaptation, and Vulnerability. Part B: Regional Aspects. Contribution of Working Group II to the Fifth Assessment Report of the Intergovernmental Panel on Climate Change; Barros, V., Field, C., Dokken, D.J., Mastrandrea, M., Mach, K., Bilir, T., Chatterjee, M., Ebi, K., Estrada, Y., Genova, R., et al., Eds.; Cambridge University Press: Cambridge, UK; New York, NY, USA, 2014; pp. 1199-1265.

71. Richard, Y.; Trzaska, S.; Roucou, P.; Rouault, M. Modification of the southern African rainfall variability / ENSO relationship since the late 1960s. Clim. Dyn. 2000, 16, 883-895.

72. Indeje, M.; Semazzi, F.H.M.; Ogallo, L.J. ENSO signals in East African rainfall seasons. Int. J. Climatol. 2000, 20, 19-46.

73. Preethi, B.; Sabin, T.P.; Adedoyin, J.A.; Ashok, K. Impacts of the ENSO Modoki and other Tropical Indo-Pacific Climate-Drivers on African Rainfall. Sci. Rep. 2015, 5, 16653.

74. Ropelewski, C.F.; Halpert, M.S. Global and Regional Scale Precipitation Patterns Associated with the El Niño/Southern Oscillation. Mon. Weather Rev. 1987, 115, 1606-1626.

75. Yang, X.; DelSole, T. Systematic comparison of enso teleconnection patterns between models and observations. J. Clim. 2012, 25, 425-446.

76. Kuenzer, C.; Zhao, D.; Scipal, K.; Sabel, D.; Naeimi, V.; Bartalis, Z.; Hasenauer, S.; Mehl, H.; Dech, S.; Wagner, W. El Niño southern oscillation influences represented in ERS scatterometer-derived soil moisture data. Appl. Geogr. 2009, 29, 463-477.

77. Manatsa, D.; Mushore, T.; Lenouo, A. Improved predictability of droughts over southern Africa using the standardized precipitation evapotranspiration index and ENSO. Theor. Appl. Climatol. 2017, 127, 259-274.

78. Ratnam, J.V.; Behera, K.; Masumoto, Y.; Yamagata, T. Remote Effects of El Niño and Modoki Events on the Austral Summer Precipitation of Southern Africa. J. Clim. 2014, 27, 3802-3815.

79. Rojas, O.; Li, Y.; Cumani, R. Understanding the Drought Impact of El Niño on the Global Agricultural Areas: An Assessment Using FAO's Agricultural Stress Index (ASI); FAO: Rome, Italy, 2014.

80. Maisongrande, P.; Duchemin, B.; Dedieu, G. VEGETATION/SPOT: An operational mission for the Earth monitoring; presentation of new standard products. Int. J. Remote Sens. 2004, 25, 9-14.

81. Dierckx, W.; Sterckx, S.; Benhadj, I.; Livens, S.; Duhoux, G.; Achteren, T.V.; Francois, M.; Mellab, K.; Saint, G. PROBA-V mission for global vegetation monitoring: Standard products and image quality. Int. J. Remote Sens. 2014, 35, 2589-2614.

82. U.S. Geological Survey (USGS). Remote Sensing Phenology. NDVI from AVHRR, 2015. Available online: https:/ / phenology.cr.usgs.gov/ndvi_avhrr.php (accessed on 10 January 2017).

83. Dinku, T.; Ceccato, P.; Grover-Kopec, E.; Lemma, M.; Connor, S.J.; Ropelewski, C.F. Validation of satellite rainfall products over East Africa's complex topography. Int. J. Remote Sens. 2007, 28, 1503-1526.

(c) 2017 by the authors. Licensee MDPI, Basel, Switzerland. This article is an open access article distributed under the terms and conditions of the Creative Commons Attribution (CC BY) license (http://creativecommons.org/licenses/by/4.0/). 